Optical nonlinearity and charge transfer analysis of 4-[(E)-2-(2,4,6-Trinitrophenyl) ethylidene] benzonitrile adsorbed on silver nanoparticles : Computational and experimental investigations

\author{
John, Jerin Susan
}

2018-11

John , J S , Sajan , D , Narayana , C \& Sundius , T 2018 , ' Optical nonlinearity and charge transfer analysis of 4-[(E)-2-(2,4,6-Trinitrophenyl) ethylidene] benzonitrile adsorbed on silver nanoparticles : Computational and experimental investigations ' , Optics \& Laser Technology , vol. 107 , pp. 454-467 . https://doi.org/10.1016/j.optlastec.2018.06.006

http://hdl.handle.net/10138/327065

https://doi.org/10.1016/j.optlastec.2018.06.006

cc_by_nc_nd

acceptedVersion

Downloaded from Helda, University of Helsinki institutional repository.

This is an electronic reprint of the original article.

This reprint may differ from the original in pagination and typographic detail.

Please cite the original version. 


\title{
Optical Nonlinearity and Charge Transfer Analysis of 4-[(E)-2-(2,4,6- Trinitrophenyl) ethylidene] benzonitrile Adsorbed on Silver Nanoparticles: Computational and Experimental Investigations
}

\author{
Jerin Susan John ${ }^{a}$, D. Sajan ${ }^{a^{*}}$, Chandrabhas Narayana ${ }^{b}$, T. Sundius ${ }^{c}$ \\ ${ }^{a}$ Centre for Advanced Functional Materials, Department of Physics, Bishop Moore College, \\ Mavelikara, Alappuzha, Kerala 690110, India \\ ${ }^{\mathrm{b}}$ Chemistry and Physics of Materials Unit, Jawaharlal Nehru Centre for Advanced Scientific \\ Research, Jakkur P.O., Bangalore 560064, India \\ ${ }^{c}$ Department of Physics, University of Helsinki, P.O. Box 64, FIN-00014 Helsinki, Finland \\ *Corresponding Author: dsajanbmc@gmail.com
}

\begin{abstract}
The search for a potential nonlinear optical (NLO) material has led to the investigation of an organic compound 4-[(E)-2-(2,4,6-Trinitrophenyl)ethylidene]benzonitrile (TEB), which has a possibility of enhancing the NLO properties by the charge transfer mechanism if metal atoms are adsorbed on it. The experimental characterization of TEB is done using Fourier Transform Infrared (FT-IR), FT-Raman, Ultraviolet-visible (UV-Visible), Photoluminescence (PL), Thermogravimetric/Differential Thermal Analysis (TG/DTA) and Zscan techniques. third order NLO properties evaluated using Z-scan technique proves that the material can be used as a good optical limiter. TEB is attached with silver atoms and the theoretical studies including geometry optimization, NBO analysis and hyperpolarizability calculations are carried out. The TEB molecule with silver atoms adsorbed is found to have increased hyperpolarizability values. The charge transfer from the metal atom to the nitrile group of the molecule is evident from the Surface Enhanced Raman Scattering (SERS) spectra using the silver nanoparticles.
\end{abstract}

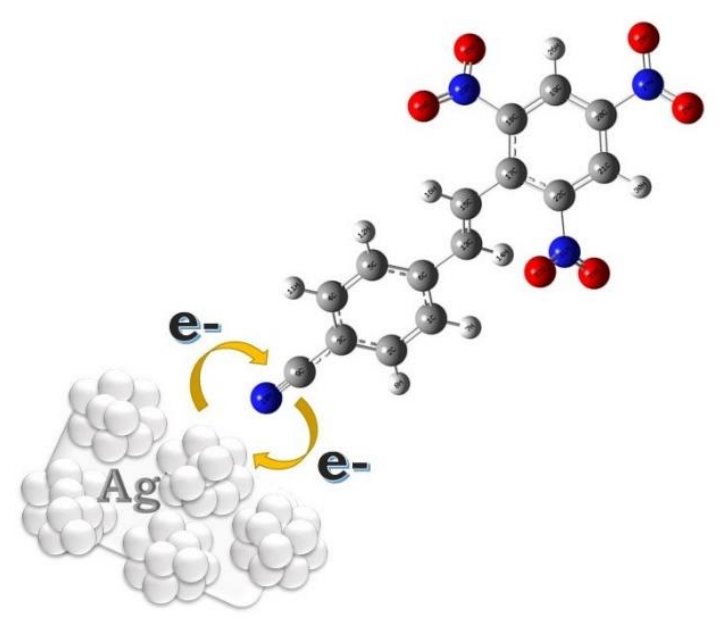

Keywords: Nonlinear optics, Silver Nanoparticles, SERS, DFT calculation 


\section{INTRODUCTION}

The synthesis of materials having good nonlinear optical (NLO) response attracts greater attention due to their potential photonic applications ${ }^{1,2}$. The third order NLO materials are used in diverse fields for optical power limiting, bio-imaging, nanophotonics, ultrafast optical switches and other optoelectronic devices, which makes the design and synthesis of such materials more important ${ }^{3,4}$. Organic NLO materials, when compared to inorganic materials, are found to have properties such as higher nonlinear optical coefficients, ease of fabrication, high laser damage threshold and relatively low $\operatorname{cost}^{5}$. The quantum computational techniques give insight into the behaviour of the molecules in terms of the bonds for interaction and can be used for designing and developing materials of desired properties with low cost and less effort. These methods use theories varying from ab initio to density functional theories (DFT) with different basis sets to match with the systems under consideration ${ }^{6-8}$. The present work is concentrated on the characterization of an organic NLO material 4-[(E)-2-(2,4,6-Trinitrophenyl)ethylidene] benzonitrile (TEB) which was originally synthesized ${ }^{9}$ for using it as an organometallic ligand for iron-phosphine complexes that can increase the NLO activity. A ligand rich in $\pi$ electrons can extend $\pi$-conjugation and increase charge transfer leading to greater values of $\beta$ hyperpolarizability ${ }^{10}$. The previous studies reveal that the co-ordination through $\mathrm{CN}$ functional group of nitrile ligand permits $\pi$ backdonation from metal d orbitals with $\pi^{*}$ orbitals of $\mathrm{CN}$ group, leading to an extension of $\pi$ electron system between the metal and the ligand ${ }^{11-13}$. These facts are being checked in the present study using the theoretical and experimental means.

Since the synthesis and X-ray diffraction studies of the ligand molecule are reported ${ }^{9}$, a detailed study regarding the third order NLO properties along with the vibrational spectroscopic characteristics are carried out in the present study. The effect of adsorption of metal atoms to the 
TEB molecule is studied theoretically and also experimentally by adsorbing silver atoms to the molecule.

\section{EXPERIMENTAL/THEORETICAL METHODS}

Synthesis and crystal growth. The compound (TEB) is synthesized as per the details given by Borger et. al. ${ }^{9}$

FT-IR, FT-Raman, UV-Vis, Photoluminescence, Thermal and Z-scan studies. The FT-IR spectrum of TEB was recorded using a Perkin Elmer spectrophotometer with $1 \mathrm{~cm}^{-1}$ spectral resolution in the wavenumber range from 4000 to $400 \mathrm{~cm}^{-1}$ with samples in the $\mathrm{KBr}$ technique. The Raman spectrum of the solid compound is recorded using $1064 \mathrm{~nm}$ laser between 4000 and $10 \mathrm{~cm}^{-1}$ with a Bruker RFS 27 spectrometer with $100 \mathrm{~mW}$ laser power and a resolution of $2 \mathrm{~cm}^{-1}$. The UV-Vis absorption spectrum of the sample is recorded in chloroform solution using a JASCO UV-Vis spectrophotometer in the spectral region of 190-1100 nm. Thermogravimetric and differential thermal analyses (TG/DTA) are carried out with the help of the Perkin Elmer instrument in nitrogen atmosphere for a $4.5 \mathrm{mg}$ sample and heating in the range of $50^{\circ} \mathrm{C}$ to $995^{\circ} \mathrm{C}$ at $10^{\circ} \mathrm{C} / \mathrm{min}$ is supplied. Photoluminescence studies are carried out at room temperature using the Horiba Scientific Inc. spectrophotometer at an excitation wavelength of $350 \mathrm{~nm}$ with Xe lamp as the excitation source. The sample in powder form is mixed in chloroform and mounted inside the chamber for the measurements. The open aperture Z-scan method is employed using laser wavelength of 532nm, pulse width 5000 ps and an average energy of $140 \mu \mathrm{J}$, to study the nonlinear absorption properties of the sample. The sample position is changed from the positive to the negative $\mathrm{z}$ direction with respect to the focus of the beam, and the transmittance value is noted for each position. 
For SERS spectrum. The colloidal silver nanoparticles are prepared by the Lee-Meisel $\operatorname{method}^{14}$, where $18 \mathrm{mg}$ of silver nitrate is mixed in $100 \mathrm{ml}$ of distilled water and boiled while stirring. To the boiled solution, $2 \mathrm{ml}$ of $1 \%$ sodium citrate solution is added dropwise and the boiling is continued for one hour. After that, the solution is cooled and used for mixing with TEB in dimethyl sulfoxide (DMSO) solution. The TEB solution of $10^{-5} \mathrm{M}$ and $10^{-6} \mathrm{M}$, and the silver sol are mixed in two ratios 1:2 and 1:4. They are drop-coated on a glass slide and made to dry for the Raman spectral measurement using LabRAM HR (UV) system with $532 \mathrm{~nm}$ wavelength in the range $4000-250 \mathrm{~cm}^{-1}$.

The silver nanoparticles are characterized using the Brookhaven Instruments Corp. ZetaPALS instrument for the measurement of particle size and zeta potential. Zeiss Ultra 55 Scanning Electron Microscope (SEM) is used to find the surface morphology of the nanoparticles.

DFT, NCA, NBO. In the present work $\mathrm{DFT}^{7}$ calculations at the B3LYP/cc-pVTZ level of theory are done to compute structural parameters and spectral details using the Gaussian'09 program package ${ }^{15}$. For the hyperpolarizability calculation, the $6-311++\mathrm{G}(\mathrm{d}, \mathrm{p})$ basis set is used with the B3LYP exchange correlation functional. The adsorption characteristics of TEB on silver atom and cluster are theoretically investigated with the LANL2DZ basis set.

By the Normal Co-ordinate Analysis (NCA), the percental contributions of internal coordinates to the normal coordinates is obtained using a normalized potential energy distribution (PED).The MOLVIB program ${ }^{16}$ is used for the IR and Raman vibrational assignments of the molecule. The Natural Bond Orbital (NBO) Analysis is carried out using the 
NBO 3.1 version $^{17}$ as implemented in the Gaussian'09 program and the second order stabilization energies ${ }^{18} \Delta E_{i j}^{(2)}$ that depict the strength of the interactions are evaluated.

Quantum Theory of Atoms in Molecules (QTAIM). The principles of quantum mechanics can be applied to predict the chemical behavior of the molecules including the strength of the hydrogen bonds using Bader's Theory of Atoms in Molecules ${ }^{19-21}$. For rank three critical points, four signatures are possible and the stable or non-degenerate critical points are represented as $(3,-3),(3,-1),(3,+1)$ and $(3,+3)$, depending on the curvature at the point. The analyses are done using AIMAll program suite ${ }^{22}$ which is developed by Todd A. Keith.

Hirshfeld Surfaces. Hirshfeld surfaces ${ }^{23}$ are a measure of the space occupied by a molecule in a crystal ${ }^{24}$. It is defined as an isosurface with $w_{i}(r)=0.5$. The parameters that we get for the Hirshfeld surfaces from the CrystalExplorer $3.1^{25}$ software are the normalized contact distance $\left(\mathrm{d}_{\text {norm }}\right)$, the shape index $(\mathrm{S})$ and the curvedness $(\mathrm{C})$, which are defined as $\mathrm{s}^{25,26}$

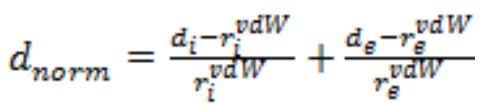

$$
\begin{aligned}
& S=\left(\frac{2}{\pi}\right) \arctan \left[\frac{\left(\kappa_{1}+\kappa_{2}\right)}{\left(\kappa_{1}-\kappa_{2}\right)}\right] \\
& C=\left(\frac{2}{\pi}\right) \ln \left[\frac{\left(\kappa_{1}^{2}+\kappa_{2}^{2}\right)}{2}\right]^{1 / 2}
\end{aligned}
$$

where $d_{i}$ is the distance from the surface to the nearest atom interior to the surface, $d_{e}$ is the distance from the surface to the nearest atom exterior to the surface, $r_{i}^{v d W}$ is the van der Waals 
$(\mathrm{vdW})$ radius of the appropriate atom internal to the surface, $r_{e}^{\mathrm{vdW}}$ is the van der Waals (vdW) radius of the appropriate atom external to the surface, $\kappa_{1} \& \kappa_{2}$ are the principal curvatures of the surfaces.

\section{RESULTS AND DISCUSSION}

\section{Molecular Structure Analysis}

(a)
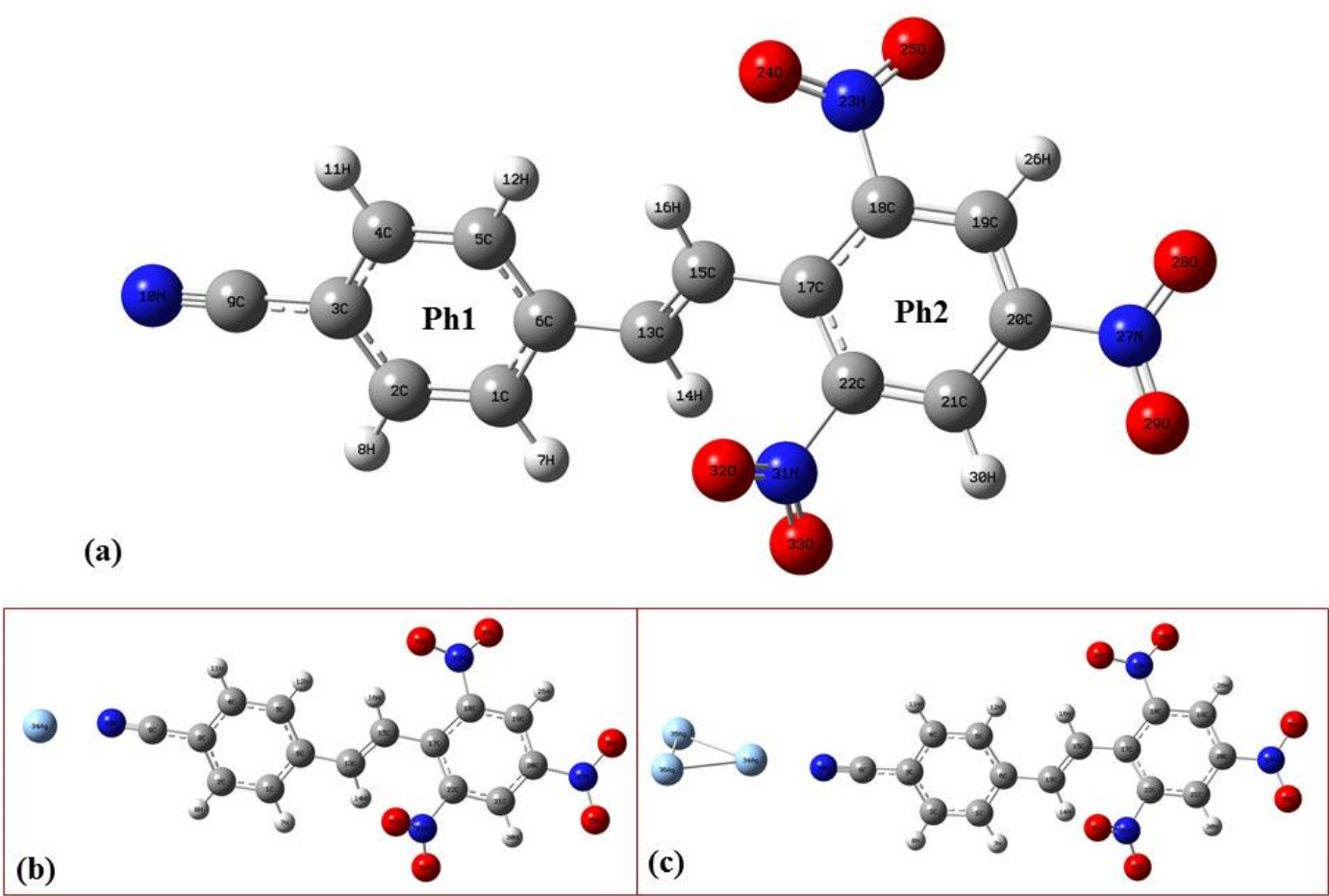

Figure 1. Optimized Molecular Geometry of (a) TEB (b) Ag-TEB and (c) $\mathrm{Ag}_{3}-\mathrm{TEB}$

The optimized structure of the TEB molecule is shown in Figure 1(a). In Table 1, the bond lengths and the bond angles obtained from geometric optimization are compared with the experimental data obtained from the previous work ${ }^{9}$ of the compound and also with the theoretical output calculated for $\mathrm{Ag}$ - and $\mathrm{Ag}_{3}$-adsorbed molecule. Since the silver atoms are attached to the TEB molecule through the $\mathrm{CN}$ group, variations are expected to the bond lengths and bond angles between the nearest neighbor atoms to the $\mathrm{CN}$ group. Due to the interaction 
between the $\mathrm{N}_{10}$ atom and the silver atoms, $\mathrm{C}_{9}-\mathrm{N}_{10}$ bond length is increased, while $\mathrm{C}_{3}-\mathrm{C}_{9}$ bond length is decreased slightly. Almost equal increase of about $0.02^{0}$ in bond lengths is observed for $\mathrm{C}_{2}-\mathrm{C}_{3}, \mathrm{C}_{3}-\mathrm{C}_{4}, \mathrm{C}_{5}-\mathrm{C}_{6}$ and $\mathrm{C}_{6}-\mathrm{C}_{1}$ bonds in the ring $\mathrm{Ph1}$, while the $\mathrm{CH}$ bonds remain almost the same. The other double bonds in the molecule also got lengthened, while the single bonds remain the same in length. We can see that the silver triangular cluster plane is oriented perpendicular to the plane of the ring $\mathrm{Ph} 1$.The bond angle of $\mathrm{Ag}_{34}-\mathrm{N}_{10}-\mathrm{C}_{9}$ to be $176.7^{0}$ reveals that the $\mathrm{Ag}_{34}$ atom is almost in line with the $\mathrm{C}_{9}-\mathrm{N}_{10}$ bond in the case of cluster attachment to the molecule. The length between the silver atoms in the cluster triangle is $2.74 \AA$ which gives an equilateral triangle with bond angles $\sim 60^{\circ}$ between them.

Table 1. Optimized geometric parameters of TEB, Ag-TEB and $\mathrm{Ag}_{3}$-TEB

\begin{tabular}{|c|c|c|c|c|c|c|c|c|c|}
\hline \multicolumn{5}{|c|}{ Bond lengths $(\AA)$} & \multicolumn{5}{|c|}{ Bond Angles $\left({ }^{0}\right)$} \\
\hline \multirow[b]{2}{*}{ Parameter } & \multirow{2}{*}{$\begin{array}{c}\text { Experi } \\
\text { mental } \\
\text { TEB }\end{array}$} & \multicolumn{3}{|c|}{ Calculated } & \multirow[b]{2}{*}{ Parameter } & \multirow{2}{*}{$\begin{array}{c}\text { Experi } \\
\text { mental } \\
\text { TEB }\end{array}$} & \multicolumn{3}{|c|}{ Calculated } \\
\hline & & TEB & $\begin{array}{c}\text { Ag- } \\
\text { TEB }\end{array}$ & $\begin{array}{c}\mathbf{A g}_{3} \\
\text { TEB }\end{array}$ & & & TEB & $\begin{array}{c}\text { Ag- } \\
\text { TEB }\end{array}$ & $\begin{array}{c}\mathbf{A g}_{3} \\
\text { TEB }\end{array}$ \\
\hline $\mathrm{C}_{1}-\mathrm{C}_{2}$ & 1.370 & 1.383 & 1.395 & 1.394 & $\mathrm{C}_{3}-\mathrm{C}_{4}-\mathrm{H}_{11}$ & 118.10 & 119.52 & 119.62 & 119.66 \\
\hline $\mathrm{C}_{2}-\mathrm{C}_{3}$ & 1.388 & 1.397 & 1.421 & 1.422 & $\mathrm{H}_{11}-\mathrm{C}_{4}-\mathrm{C}_{5}$ & 121.80 & 120.31 & 120.21 & 120.15 \\
\hline $\mathrm{C}_{3}-\mathrm{C}_{4}$ & 1.381 & 1.401 & 1.423 & 1.425 & $\mathrm{C}_{13}-\mathrm{C}_{15}-\mathrm{H}_{16}$ & 122.30 & 120.81 & 119.71 & 119.13 \\
\hline $\mathrm{C}_{4}-\mathrm{C}_{5}$ & 1.371 & 1.380 & 1.393 & 1.391 & $\mathrm{H}_{16}-\mathrm{C}_{15}-\mathrm{C}_{17}$ & 113.60 & 115.79 & 115.22 & 114.76 \\
\hline $\mathrm{C}_{5}-\mathrm{C}_{6}$ & 1.389 & 1.403 & 1.425 & 1.428 & $\mathrm{C}_{5}-\mathrm{C}_{6}-\mathrm{C}_{13}$ & 120.14 & 123.29 & 123.38 & 123.41 \\
\hline $\mathrm{C}_{6}-\mathrm{C}_{1}$ & 1.395 & 1.401 & 1.423 & 1.426 & $\mathrm{C}_{1}-\mathrm{C}_{6}-\mathrm{C}_{13}$ & 121.71 & 118.42 & 118.54 & 118.74 \\
\hline $\mathbf{C}_{1}-\mathbf{H}_{7}$ & 0.950 & 1.081 & 1.087 & 1.087 & $\mathrm{C}_{6}-\mathrm{C}_{13}-\mathrm{C}_{15}$ & 124.83 & 126.37 & 125.45 & 124.97 \\
\hline $\mathrm{C}_{2}-\mathrm{H}_{8}$ & 0.910 & 1.080 & 1.086 & 1.086 & $\mathrm{C}_{15}-\mathrm{C}_{17}-\mathrm{C}_{18}$ & 121.90 & 123.36 & 122.91 & 122.62 \\
\hline $\mathrm{C}_{3}-\mathrm{C}_{9}$ & 1.437 & 1.427 & 1.424 & 1.421 & $\mathrm{C}_{15}-\mathrm{C}_{17}-\mathrm{C}_{22}$ & 124.53 & 122.42 & 123.37 & 123.76 \\
\hline $\mathrm{C}_{6}-\mathrm{C}_{13}$ & 1.464 & 1.460 & 1.459 & 1.455 & $\mathrm{C}_{17}-\mathrm{C}_{18}-\mathrm{C}_{19}$ & 125.10 & 123.45 & 123.26 & 123.12 \\
\hline $\mathrm{C}_{9}-\mathrm{N}_{10}$ & 1.139 & 1.152 & 1.186 & 1.182 & $\mathrm{C}_{17}-\mathrm{C}_{18}-\mathrm{N}_{23}$ & 119.60 & 121.42 & 122.40 & 122.68 \\
\hline $\mathrm{C}_{13}-\mathrm{C}_{15}$ & 1.312 & 1.341 & 1.369 & 1.373 & $\mathrm{~N}_{23}-\mathrm{C}_{18}-\mathrm{C}_{19}$ & 115.15 & 115.07 & 114.31 & 114.17 \\
\hline $\mathrm{C}_{15}-\mathrm{C}_{17}$ & 1.472 & 1.465 & 1.460 & 1.454 & $\mathrm{C}_{18}-\mathrm{N}_{23}-\mathrm{O}_{24}$ & 116.50 & 118.01 & 119.29 & 119.46 \\
\hline $\mathrm{C}_{17}-\mathrm{C}_{22}$ & 1.401 & 1.406 & 1.433 & 1.438 & $\mathrm{H}_{26}-\mathrm{C}_{19}-\mathrm{C}_{20}$ & 125.10 & 120.70 & 120.52 & 120.43 \\
\hline $\mathrm{C}_{17}-\mathrm{C}_{18}$ & 1.397 & 1.410 & 1.438 & 1.444 & $\mathrm{C}_{21}-\mathrm{C}_{22}-\mathrm{C}_{17}$ & 123.62 & 124.29 & 124.55 & 124.50 \\
\hline $\mathrm{C}_{18}-\mathrm{N}_{23}$ & 1.472 & 1.483 & 1.478 & 1.474 & $\mathrm{C}_{17}-\mathrm{C}_{22}-\mathrm{N}_{31}$ & 120.48 & 120.43 & 121.19 & 121.43 \\
\hline $\mathrm{N}_{23}-\mathrm{O}_{24}$ & 1.217 & 1.220 & 1.284 & 1.287 & $\mathrm{C}_{22}-\mathrm{N}_{31}-\mathrm{O}_{32}$ & 116.40 & 117.08 & 118.44 & 118.63 \\
\hline $\mathrm{N}_{23}-\mathrm{O}_{25}$ & 1.206 & 1.217 & 1.281 & 1.285 & $\mathrm{C}_{22}-\mathrm{N}_{31}-\mathrm{O}_{33}$ & 119.96 & 116.56 & 117.18 & 117.35 \\
\hline $\mathrm{C}_{22}-\mathrm{N}_{31}$ & 1.484 & 1.484 & 1.484 & 1.481 & $\mathrm{O}_{24}-\mathrm{N}_{23}-\mathrm{O}_{25}$ & 125.80 & 125.22 & 123.02 & 122.58 \\
\hline $\mathrm{N}_{31}-\mathrm{O}_{32}$ & 1.211 & 1.214 & 1.276 & 1.278 & $\mathrm{O}_{32}-\mathrm{N}_{31}-\mathrm{O}_{33}$ & 123.60 & 126.31 & 124.32 & 123.96 \\
\hline $\mathrm{N}_{31}-\mathrm{O}_{33}$ & 1.200 & 1.220 & 1.282 & 1.284 & $\mathrm{O}_{28}-\mathrm{N}_{27}-\mathrm{O}_{29}$ & 123.70 & 125.67 & 124.28 & 123.99 \\
\hline
\end{tabular}


Natural Bond Orbital Analysis. The charge transfer interactions of TEB, Ag-TEB and $\mathrm{Ag}_{3}$-TEB by NBO analysis are demonstrated in Table 2. Taking simple TEB separately, it can be observed that the charge transfer between the $\pi$ and $\pi^{*}$ orbitals of alternate bonds of the phenyl ring $1(\mathrm{Ph} 1)$ has the stabilization energy in the range of $80-85 \mathrm{~kJ} / \mathrm{mol}$. The transfer of charge between $\mathrm{C}_{13}-\mathrm{C}_{15}$ and the phenyl rings contributes less energy when compared to the other $\pi(\mathrm{C}-\mathrm{C})$ to $\pi^{*}(\mathrm{C}-\mathrm{C})$ transitions inside the rings. A $\pi \rightarrow \pi^{*}$ interaction is observed between the $\pi$ orbital of $\mathrm{C}_{3}-\mathrm{C}_{4}$ and the triple bond of the nitrile group $\mathrm{C}_{9}-\mathrm{N}_{10}$ with considerable energy in the case of $\mathrm{Ag}$ attached molecules. Lone pairs of nitrogen and oxygen interact with anti-bonding $\sigma$ orbitals of the $\mathrm{CC}, \mathrm{CN}$ and $\mathrm{NO}$ bonds. The $\mathrm{N}_{10}$ lone pair transfers charge to the adjacent $\mathrm{C}_{3}-\mathrm{C}_{9} \sigma^{*}$ orbital, where the $\mathrm{CN}$ group is linearly attached to $\mathrm{Ph} 1$ of TEB. The oxygen $\mathrm{n}_{2}$ lone pairs of the nitro groups transfer charge to $\sigma^{*} \mathrm{CN}$ bonds and also to the respective other NO bonds $\left(\sigma^{*}\right)$ with a stabilization energy of $60-70 \mathrm{~kJ} / \mathrm{mol}$ and $80-82 \mathrm{~kJ} / \mathrm{mol}$, respectively. All these interactions are observed for Ag attached molecule also, but with less energy contribution. From the table, it is clear that the transitions from lone pair $\left(n_{3}\right)$ of oxygen atom to $\pi^{*}$ orbital of the three N-O bonds have the greatest energies of all the other transitions, which is much higher $(>650 \mathrm{~kJ} / \mathrm{mol}$ for a normal molecule). A weak interaction is observed between the lone pairs of the silver atoms and the $\pi^{*}$ orbital of $\mathrm{C}_{9}-\mathrm{N}_{10}$ which can be taken as a confirmation of the charge transfer interaction between the metal to the TEB molecule.

Table 2. NBO Analysis of TEB, Ag-TEB and $\mathrm{Ag}_{3}-\mathrm{TEB}$

\begin{tabular}{|c|c|c|c|c|}
\hline \multirow{2}{*}{$\begin{array}{l}\text { Donor NBO } \\
\text { (i) }\end{array}$} & \multirow{2}{*}{$\begin{array}{l}\text { Acceptor NBO } \\
(\text { (j) }\end{array}$} & \multicolumn{3}{|c|}{ Energy Density, E(2) kJ/mol } \\
\hline & & TEB & Ag-TEB & Ag3-TEB \\
\hline$\pi\left(\mathbf{C}_{1}-\mathbf{C}_{2}\right)$ & $\pi *\left(\mathrm{C}_{3}-\mathrm{C}_{4}\right)$ & 83.136 & 40.668 & 40.919 \\
\hline$\pi\left(C_{1}-C_{2}\right)$ & $\pi *\left(\mathrm{C}_{5}-\mathrm{C}_{6}\right)$ & 86.148 & 45.019 & 43.346 \\
\hline$\pi\left(C_{3}-C_{4}\right)$ & $\pi *\left(\mathrm{C}_{1}-\mathrm{C}_{2}\right)$ & 82.010 & 41.756 & 40.584 \\
\hline
\end{tabular}




\begin{tabular}{|c|c|c|c|c|}
\hline$\pi\left(C_{3}-C_{4}\right)$ & $\pi^{*}\left(\mathrm{C}_{5}-\mathrm{C}_{6}\right)$ & 84.182 & 40.250 & 40.083 \\
\hline$\pi\left(\mathrm{C}_{5}-\mathrm{C}_{6}\right)$ & $\pi^{*}\left(\mathrm{C}_{1}-\mathrm{C}_{2}\right)$ & 76.693 & 36.861 & 37.321 \\
\hline$\pi\left(C_{5}-C_{6}\right)$ & $\pi^{*}\left(\mathrm{C}_{3}-\mathrm{C}_{4}\right)$ & 97.780 & 57.781 & 59.287 \\
\hline$\pi\left(C_{5}-C_{6}\right)$ & $\pi^{*}\left(\mathrm{C}_{13}-\mathrm{C}_{15}\right)$ & 50.835 & 26.526 & 26.359 \\
\hline$\pi\left(C_{13}-C_{15}\right)$ & $\pi^{*}\left(\mathrm{C}_{5}-\mathrm{C}_{6}\right)$ & 45.019 & 29.329 & 30.919 \\
\hline$\pi\left(\mathrm{C}_{3}-\mathrm{C}_{4}\right)$ & $\pi^{*}(3)\left(\mathrm{C}_{9}-\mathrm{N}_{10}\right)$ & 72.216 & 53.848 & 57.446 \\
\hline $\mathbf{n}_{1}\left(\mathbf{N}_{10}\right)$ & $\sigma^{*}\left(\mathrm{C}_{3}-\mathrm{C}_{9}\right)$ & 63.011 & 23.556 & 20.208 \\
\hline $\mathbf{n}_{2}\left(\mathbf{O}_{24}\right)$ & $\sigma^{*}\left(\mathrm{C}_{18}-\mathrm{N}_{23}\right)$ & 65.103 & 19.706 & 18.577 \\
\hline $\mathbf{n}_{2}\left(\mathbf{O}_{25}\right)$ & $\sigma^{*}\left(\mathrm{C}_{18}-\mathrm{N}_{23}\right)$ & 69.789 & 23.807 & 23.263 \\
\hline $\mathbf{n}_{2}\left(\mathbf{O}_{28}\right)$ & $\sigma^{*}\left(\mathrm{C}_{20}-\mathrm{N}_{27}\right)$ & 69.371 & 22.301 & 21.506 \\
\hline $\mathbf{n}_{2}\left(\mathrm{O}_{29}\right)$ & $\sigma^{*}\left(\mathrm{C}_{20}-\mathrm{N}_{27}\right)$ & 68.659 & 21.798 & 21.004 \\
\hline $\mathbf{n}_{2}\left(\mathrm{O}_{32}\right)$ & $\sigma^{*}\left(\mathrm{C}_{22}-\mathrm{N}_{31}\right)$ & 68.827 & 23.807 & 23.263 \\
\hline $\mathbf{n}_{2}\left(\mathbf{O}_{33}\right)$ & $\sigma^{*}\left(\mathrm{C}_{22}-\mathrm{N}_{31}\right)$ & 64.852 & 21.798 & 21.422 \\
\hline $\mathbf{n}_{2}\left(\mathbf{O}_{24}\right)$ & $\sigma^{*}\left(\mathrm{~N}_{23}-\mathrm{O}_{25}\right)$ & 81.253 & 37.949 & 37.698 \\
\hline $\mathbf{n}_{2}\left(\mathbf{O}_{25}\right)$ & $\sigma^{*}\left(\mathrm{~N}_{23}-\mathrm{O}_{24}\right)$ & 81.002 & 36.861 & 36.652 \\
\hline $\mathbf{n}_{2}\left(\mathrm{O}_{28}\right)$ & $\sigma^{*}\left(\mathrm{~N}_{27}-\mathrm{O}_{29}\right)$ & 81.379 & 37.614 & 37.488 \\
\hline $\mathbf{n}_{2}\left(\mathbf{O}_{29}\right)$ & $\sigma^{*}\left(\mathrm{~N}_{27}-\mathrm{O}_{28}\right)$ & 81.086 & 37.405 & 37.237 \\
\hline $\mathbf{n}_{2}\left(\mathbf{O}_{32}\right)$ & $\sigma^{*}\left(\mathrm{~N}_{31}-\mathrm{O}_{33}\right)$ & 82.676 & 38.032 & 37.865 \\
\hline $\mathbf{n}_{2}\left(\mathbf{O}_{33}\right)$ & $\sigma^{*}\left(\mathrm{~N}_{31}-\mathrm{O}_{32}\right)$ & 80.207 & 37.196 & 36.986 \\
\hline $\mathbf{n}_{3}\left(\mathbf{O}_{24}\right)$ & $\pi^{*}\left(\mathrm{~N}_{23}-\mathrm{O}_{25}\right)$ & 686.971 & 309.867 & 297.733 \\
\hline $\mathbf{n}_{3}\left(\mathbf{O}_{29}\right)$ & $\pi^{*}\left(\mathrm{~N}_{27}-\mathrm{O}_{28}\right)$ & 705.171 & - & - \\
\hline $\mathbf{n}_{\mathbf{3}}\left(\mathbf{O}_{\mathbf{3 3}}\right)$ & $\pi^{*}\left(\mathrm{~N}_{31}-\mathrm{O}_{32}\right)$ & 656.721 & - & - \\
\hline $\mathbf{n}_{4}\left(\operatorname{Ag}_{34}\right)$ & $\pi^{*}\left(\mathrm{C}_{9}-\mathrm{N}_{10}\right)$ & - & 2.636 & 4.184 \\
\hline $\mathbf{n}_{5}\left(\operatorname{Ag}_{34}\right)$ & $\pi^{*}(3)\left(\mathrm{C}_{9}-\mathrm{N}_{10}\right)$ & - & 3.431 & 3.640 \\
\hline
\end{tabular}

Quantum Theory of Atoms in Molecules. This theory is based upon the analysis of the electron charge density accumulated between the bonds. The positions of bond critical points (BCP) can give information about hydrogen bonding ${ }^{20}$ and Van der Waals interaction present in the molecule. The three types of critical points present in TEB are the nuclear attractor critical point (NACP) centered on each nucleus and denoted as $(3,-3)$, the bond critical point $(\mathrm{BCP})$ present in between the bonds and denoted as $(3,-1)$ and the ring critical point $(\mathrm{RCP})$ usually present in the centre of a ring and denoted as $(3,+1)$. 
The ellipticity factor appears only in the case of $\mathrm{BCP}$ since the two other types are represented by rings or circles. Here we take into consideration the $(3,-1)$ type of critical point which is the bond critical point. Table 3 shows a clear-cut evidence for the presence of a weak intramolecular hydrogen bond, between $\mathrm{O}_{24}$ and $\mathrm{H}_{16}$ whose value of electron density is 0.0178 a.u., which indicates hydrogen bonding when $\rho \sim 10^{-2}$ a.u. ${ }^{27}$. Also, the value of $\nabla^{2} \rho$ is greater than zero for $\mathrm{O}_{24}-\mathrm{H}_{16}$, which agrees with the theory of AIM for hydrogen bonding. All the other values of $\nabla^{2} \rho$ are less than zero, which approves the covalent nature of the other bonds in the molecule and the values of $\rho>0.1$ a.u. support the covalent nature of these bonds. The signs of the non-zero eigenvalues of the Hessian matrix, represented as $\lambda_{1}, \lambda_{2}$ and $\lambda_{3}$ in the table, explains how the $\mathrm{BCP}$ got its signature. The maximum charge density exists in the NO bonds, which have a $\rho$ value of about 0.51 a.u., which is the maximum in the case of TEB. The only triple bond in the molecule is present in the nitrile group and it also has a high $\rho$ value of 0.49 a.u. The table shows that $\mathrm{CN}$ bond has the lowest $\nabla^{2} \rho$ value and the ellipticity values show that $\mathrm{CN}$ is having

the lowest value if all the $\mathrm{CH}$ bonds are excepted. All the $\mathrm{C}-\mathrm{C}$ bonds are having the electron density value of about 0.3 a.u. while the ellipticity values differs for those bonds inside the rings and those that are outside the rings. The positions of BCPs and RCPs are depicted in Figure 2(a). There are 35 BCPs for TEB, represented in green, while the three RCPs are shown as red balls in the centre of the rings. The intramolecular hydrogen bond between $\mathrm{O}_{24}$ and $\mathrm{H}_{16}$ is shown as dotted line and such a bond creates an additional ring for TEB which resulted in the third RCP. 


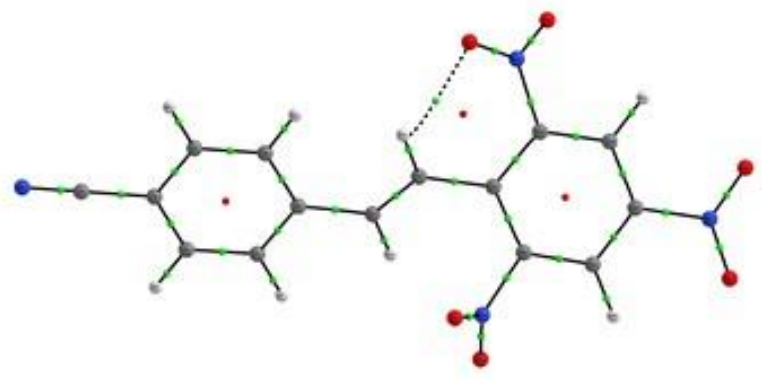

(a)

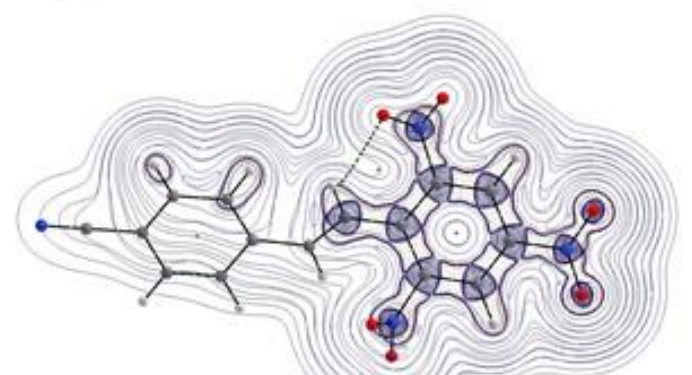

(c)

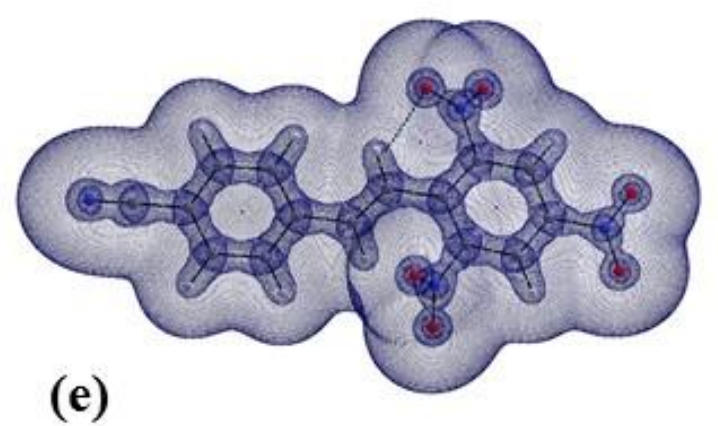

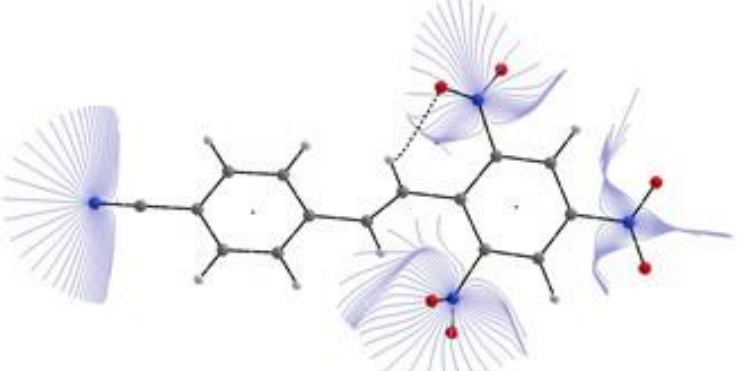

(b)

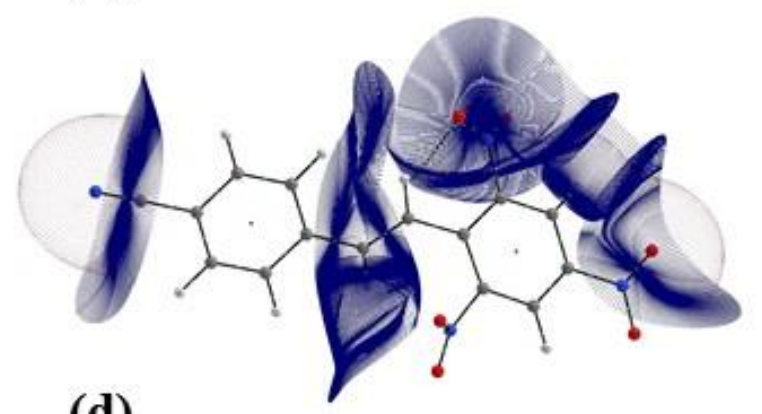

(d)

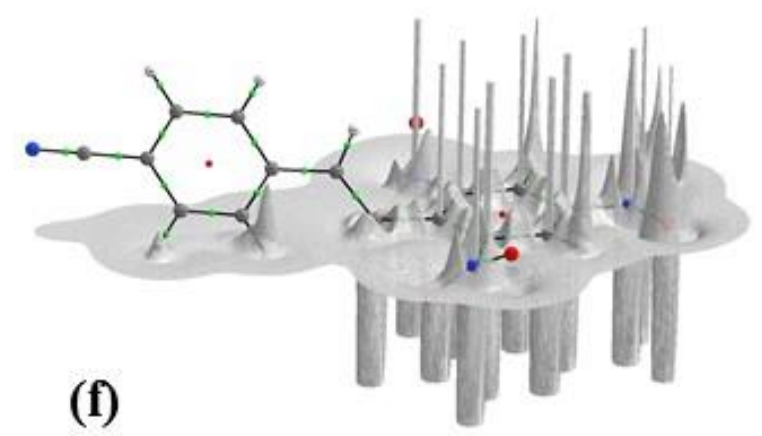

Figure 2. AIMAll Results

The atomic basins that represent the region of space belonging to the atom are shown in Figure 2(b) for the atoms $\mathrm{N}_{10}, \mathrm{~N}_{23}, \mathrm{~N}_{27}$ and $\mathrm{N}_{31}$. The basin paths of the atomic basin are the trajectories of the gradient of electron density that originate at the bond critical point. Figure 2(c) is the contour representing the Laplacian of the electron density. The interatomic surfaces centered on the atoms $\mathrm{N}_{10}, \mathrm{C}_{13}, \mathrm{~N}_{23}, \mathrm{~N}_{31}$ and $\mathrm{H}_{26}$ are shown in Figure 2(d). The isosurface of the 
electron density and Laplacian of electron density is shown in Figure 2(e); the outer surface corresponds to the isosurface of density while the inner surface represents the Laplacian isosurface. The variation in the Laplacian of electron density from the plane of the ring $\mathrm{Ph} 2$ is shown as a relief map in Figure 2(f) that represents peaks of charge concentration (negative Laplacian) and charge depletion (positive Laplacian).

Table 3. QTAIM Bond Critical Points

\begin{tabular}{|c|c|c|c|c|c|c|}
\hline \multirow{2}{*}{ BCP $(3,-1)$} & \multirow{2}{*}{$\begin{array}{c}\text { Electron } \\
\text { Density } \\
\rho\end{array}$} & \multirow{2}{*}{$\begin{array}{c}\text { Laplacian of } \\
\text { electron density } \\
\qquad \nabla^{2} \rho\end{array}$} & \multicolumn{3}{|c|}{ Eigenvalues of Hessian of $\rho$} & \multirow{2}{*}{$\begin{array}{c}\text { Ellipticity } \\
\varepsilon\end{array}$} \\
\hline & & & $\lambda_{1}$ & $\lambda_{2}$ & $\lambda_{3}$ & \\
\hline $\mathrm{C}_{1}-\mathrm{C}_{2}$ & 0.3280 & -1.1035 & -0.7405 & -0.6181 & 0.2550 & 0.1980 \\
\hline $\mathrm{C}_{4}-\mathrm{C}_{5}$ & 0.3296 & -1.1108 & -0.7446 & -0.6173 & 0.2511 & 0.2062 \\
\hline $\mathrm{C}_{5}-\mathrm{C}_{6}$ & 0.3160 & -1.0257 & -0.7029 & -0.6004 & 0.2777 & 0.1707 \\
\hline $\mathrm{C}_{3}-\mathrm{C}_{9}$ & 0.2909 & -0.9277 & -0.6121 & -0.5727 & 0.2570 & 0.0687 \\
\hline $\mathrm{C}_{6}-\mathrm{C}_{13}$ & 0.2837 & -0.8422 & -0.6092 & -0.5596 & 0.3266 & 0.0884 \\
\hline $\mathrm{C}_{13}-\mathrm{C}_{15}$ & 0.3524 & -1.2364 & -0.8135 & -0.6231 & 0.2001 & 0.3055 \\
\hline $\mathrm{C}_{15}-\mathrm{C}_{17}$ & 0.2776 & -0.8066 & -0.5832 & -0.5409 & 0.3176 & 0.0782 \\
\hline $\mathrm{C}_{17}-\mathrm{C}_{18}$ & 0.3100 & -0.9732 & -0.6888 & -0.5709 & 0.2865 & 0.2064 \\
\hline $\mathrm{C}_{18}-\mathrm{C}_{19}$ & 0.3277 & -1.0925 & -0.7373 & -0.6097 & 0.2545 & 0.2092 \\
\hline $\mathrm{C}_{19}-\mathrm{C}_{20}$ & 0.3304 & -1.1180 & -0.7475 & -0.6229 & 0.2525 & 0.2000 \\
\hline $\mathrm{C}_{17}-\mathrm{C}_{22}$ & 0.3121 & -0.9869 & -0.6941 & -0.5739 & 0.2812 & 0.2093 \\
\hline $\mathrm{C}_{9}-\mathrm{N}_{10}$ & 0.4931 & -0.2262 & -1.1352 & -1.1082 & 2.0173 & 0.0243 \\
\hline $\mathrm{N}_{27}-\mathrm{C}_{20}$ & 0.2643 & -0.7152 & -0.5764 & -0.5044 & 0.3657 & 0.1426 \\
\hline $\mathrm{N}_{23}-\mathrm{C}_{18}$ & 0.2609 & -0.7003 & -0.5621 & -0.5000 & 0.3618 & 0.1241 \\
\hline $\mathrm{N}_{31}-\mathrm{C}_{22}$ & 0.2619 & -0.7126 & -0.5590 & -0.5186 & 0.3650 & 0.0779 \\
\hline $\mathrm{N}_{27}-\mathrm{O}_{28}$ & 0.5143 & -1.1802 & -1.4321 & -1.2866 & 1.5385 & 0.1131 \\
\hline $\mathrm{N}_{23}-\mathrm{O}_{24}$ & 0.5116 & -1.1696 & -1.4287 & -1.2766 & 1.5357 & 0.1191 \\
\hline $\mathrm{N}_{31}-\mathrm{O}_{32}$ & 0.5195 & -1.2225 & -1.4572 & -1.2950 & 1.5297 & 0.1252 \\
\hline $\mathrm{C}_{1}-\mathrm{H}_{7}$ & 0.2950 & -1.1827 & -0.8325 & -0.8220 & 0.4717 & 0.0128 \\
\hline $\mathrm{C}_{13}-\mathrm{H}_{14}$ & 0.2948 & -1.1764 & -0.8284 & -0.8213 & 0.4734 & 0.0086 \\
\hline $\mathrm{C}_{15}-\mathrm{H}_{16}$ & 0.3001 & -1.2196 & -0.8667 & -0.8512 & 0.4983 & 0.0181 \\
\hline $\mathrm{C}_{19}-\mathrm{H}_{26}$ & 0.3009 & -1.2472 & -0.8899 & -0.8835 & 0.5261 & 0.0072 \\
\hline $\mathrm{O}_{24}-\mathrm{H}_{16}$ & 0.0178 & 0.0747 & -0.0189 & -0.0146 & 0.1084 & 0.2927 \\
\hline
\end{tabular}

Hirshfeld Surface Analysis. By this analysis, we get a continuous overlapping atomic charge distribution, differing from the QTAIM where the density distribution is not continuous. Also, the proximity of the neighbouring atoms is considered in this analysis. The charge 
distribution that we obtain from Hirshfeld analysis is the neutral atomic charges, since the promolecule is made up of overlapping ground-state atoms. Figure 3 shows the Hirshfeld surfaces obtained from the CrystalExplorer 3.1 software. Figure $3(\mathrm{a})$ is the $d_{\text {norm }}$ surface formed from $d_{e}$ and $d_{i}$ as per equation (6).
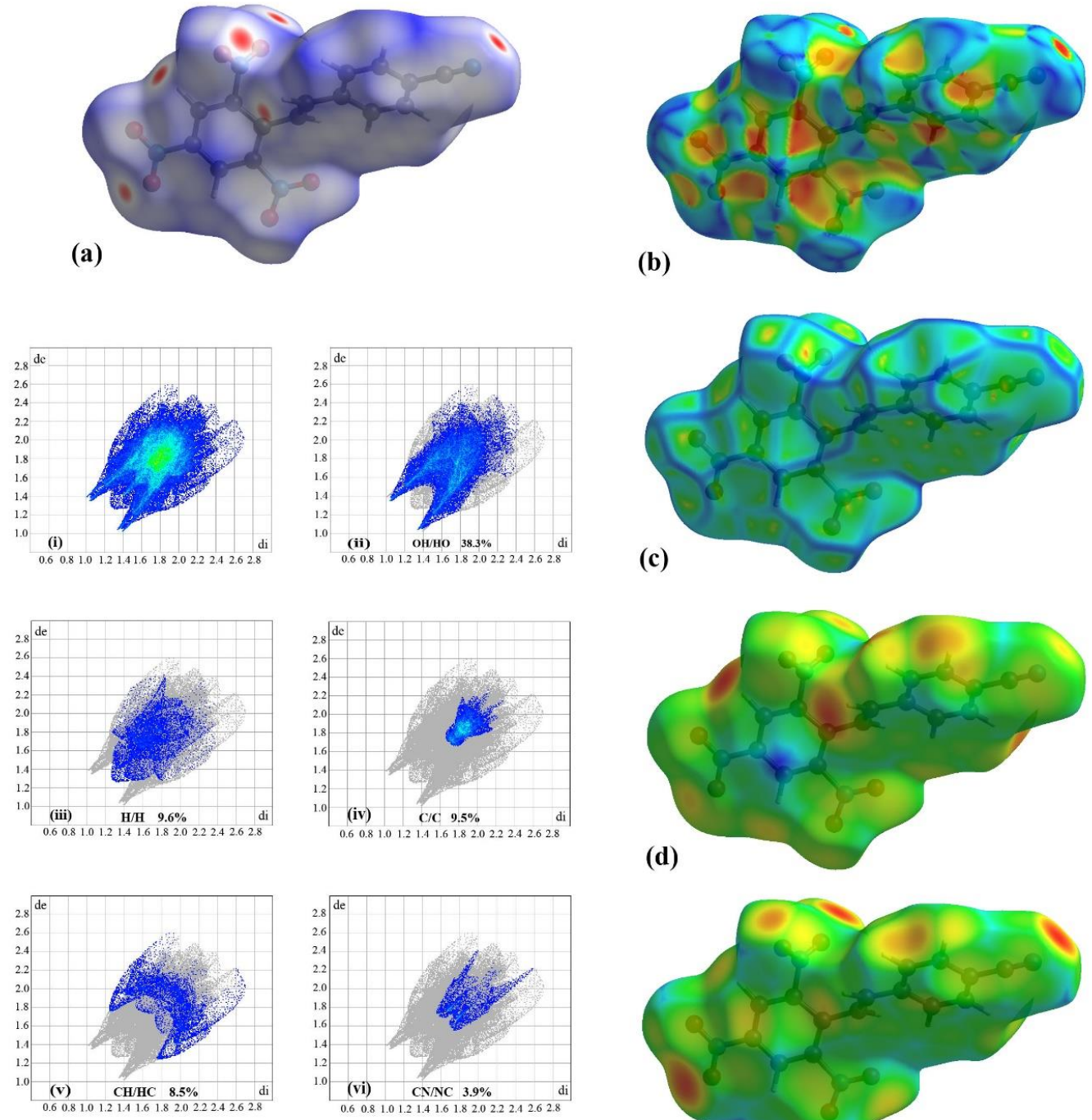

(f)

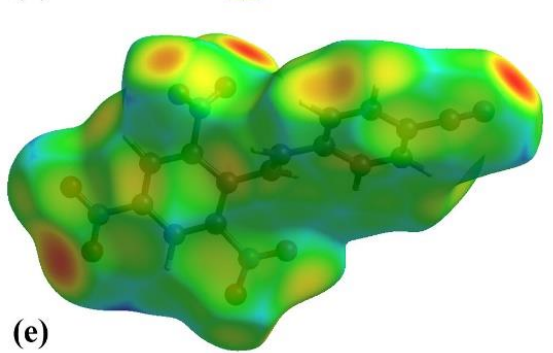

Figure 3: Hirshfeld Surface Analysis 
The normalized contact distance, $d_{\text {norm }}$, is a measure of the close contacts in the crystal.

The shorter contacts are displayed in red colour on the $d_{\text {norm }}$ surface while the longer ones are

blue in colour and the white portion represents the contacts around the Van der Waals separation. Interactions with neighboring molecules occur through the short contacts. On analyzing the whole $3 \mathrm{D} \mathrm{d}_{\text {norm }}$ surface of TEB, eight red spots are detected; four spots near the oxygen atoms of the nitro groups, three spots near the hydrogen atoms and another one near the nitrogen atom of the nitrile group. These spots can be used for determining the strength of the hydrogen bond and the proximity of the intermolecular contacts in the crystal. The possibility of the metal atom to make contact with the molecule through the nitrile group is evident from this analysis also. The shape index gives information regarding the shape of the molecular surface. If two shapes differ in shape index value only by a sign, then it represents complementary 'stamp' and 'mould' pairs. The complementary hollows (red) and bumps (blue) in the shape index map indicates the place where two molecular Hirshfeld surfaces touch one another ${ }^{23}$. The red and blue triangular patterns on the surface indicates the stacking arrangement of the ring. As seen from the equation (8), the curvedness $\mathrm{C}$ is a function of the root-mean-square of curvature of the surface and it measures the magnitude of surface curvature. Large regions of green in Figure 3(c) separated by dark blue edges indicate the relative curvature measure, where the green colour represents r.m.s. curvature of unity and the blue colour represents large r.m.s. curvature. Small traits of yellow and red indicates unusually flat regions. The map represents areas on the surface that have close contact between two molecular Hirshfeld surfaces. The surfaces formed by $d_{i}$ and $d_{e}$ separately are also shown in Figure 3(d) and Figure 3(e), respectively. The finger print plot of the 3D molecular 
structure is another entity related to the Hirshfeld surface and gives information about the contribution of each type of bond to the total molecule.

Absorption and Emission Properties. UV-Visible Spectroscopy and Frontier Molecular Orbital Analysis. The electronic transition of the molecule, generally from the Highest Occupied Molecular Orbital (HOMO) to the Lowest Unoccupied Molecular Orbital (LUMO) gives information about the absorption properties of the molecule through the ultraviolet-visible (UVVis) spectrum.

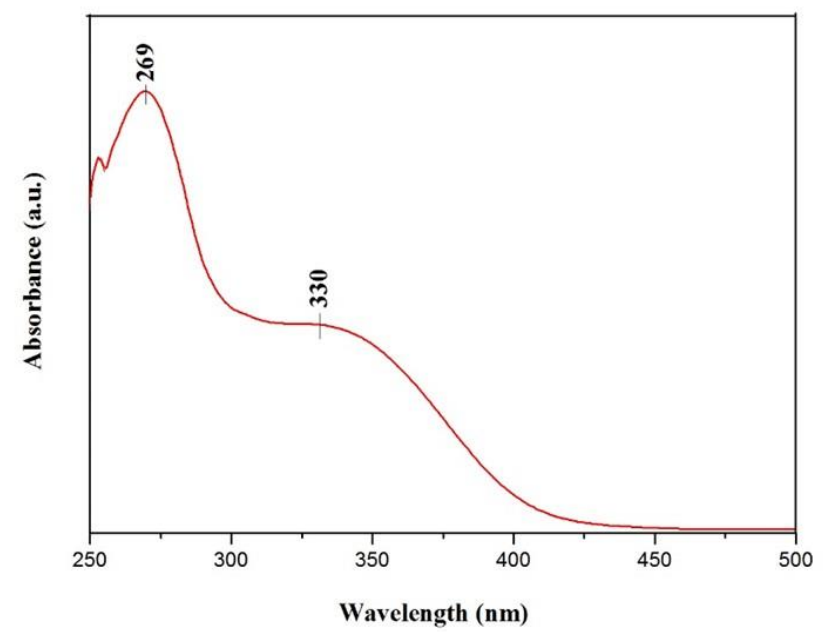

(a)

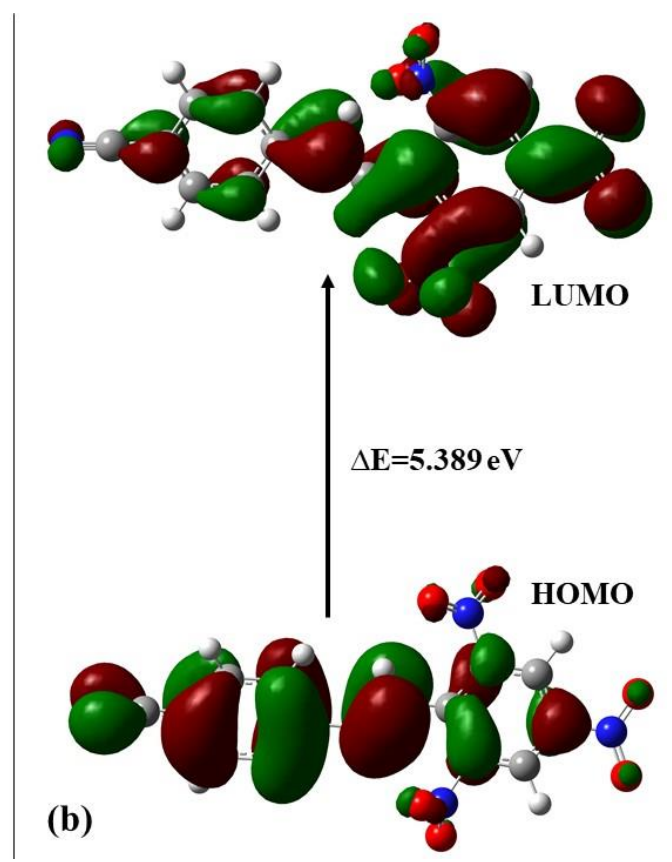

Figure 4. (a) Experimental UV-Vis Spectrum of TEB (b) HOMO-LUMO Transition

In the experimental UV-Vis spectrum (Figure 4(a)) with chloroform as the solvent for TEB, two peaks are observed, one at $269 \mathrm{~nm}$ and the other at $330 \mathrm{~nm}$. The peak at $269 \mathrm{~nm}$ with higher intensity is an allowed $\pi \rightarrow \pi^{*}$ transition while the peak at $330 \mathrm{~nm}$ with less intensity is a forbidden $n \rightarrow \pi^{*}$ transition. The Time Dependent Density Functional Theory (TD-DFT) calculations using BHandHLYP functional and the cc-pVTZ basis set result in an absorption maximum at $335 \mathrm{~nm}$ with an oscillator strength of 0.746. From the HOMO-LUMO analysis, it is 
found that the Highest Occupied Molecular Orbital (HOMO) is concentrated on the first phenyl ring $\mathrm{Ph} 1$ and the Lowest Unoccupied Molecular Orbital (LUMO) is centered on the $\mathrm{Ph} 2$ ring. The HOMO energy of TEB is obtained as -0.30536 a.u. and the LUMO energy as -0.10778 a.u., and the energy gap is computed to be 0.198 a.u., i.e., $5.389 \mathrm{eV}(1$ a.u. $=1$ Hartree $=27.2114 \mathrm{eV})$. The lesser value of energy gap makes it easy for the electron to transfer from the occupied energy level of $\mathrm{Ph} 1$ ring to the unoccupied energy level of $\mathrm{Ph} 2$ ring, and results in better NLO properties. Similar values of absorption maxima and energy gap are obtained for TD-DFT calculations using M062X functional and very close values are resulted from CAM-B3LYP calculations. ${ }^{24,25}$ The HOMO and LUMO energies of Ag-TEB are -0.17581 a.u. and -0.15707 a.u. respectively and the energy gap is calculated to be $0.510 \mathrm{eV}$. Similarly, the energy gap for $\mathrm{Ag}_{3}$-TEB is $0.360 \mathrm{eV}$ which is the lowest value of all the energy gaps computed here.

Photoluminescence Studies. The electronic energy band structure of TEB can be explored using photoluminescence studies. The luminescence, being an internal property of the molecule, is affected by the localized $\pi$-electron system of TEB molecule. The sample is dissolved in chloroform and the solution is analyzed for photoluminescence studies. When excited with a wavelength, $\lambda_{\text {exc }}$, of $350 \mathrm{~nm}$, the photoluminescence spectrum shows an intense green light emission at $528 \mathrm{~nm}$ as shown in Figure 5(a). The green light emission suggests that the molecule can be used for potential applications as OLEDs and fluorescent systems. The colour that is obtained from the CIE co-ordinates $(0.297,0.487,0.216)$ of the molecule is shown in the chromaticity diagram (Figure 5(b)). 


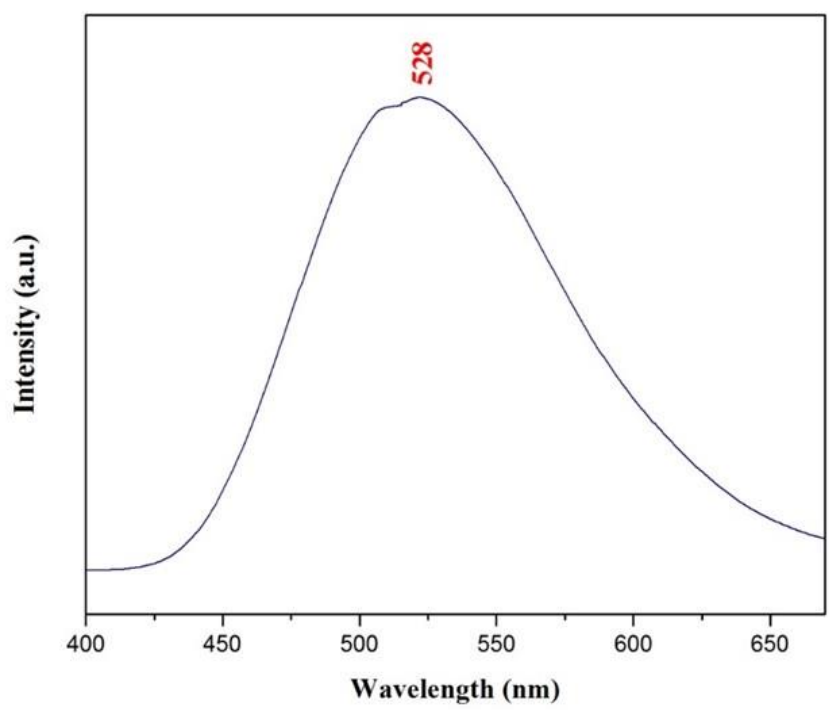

(a)

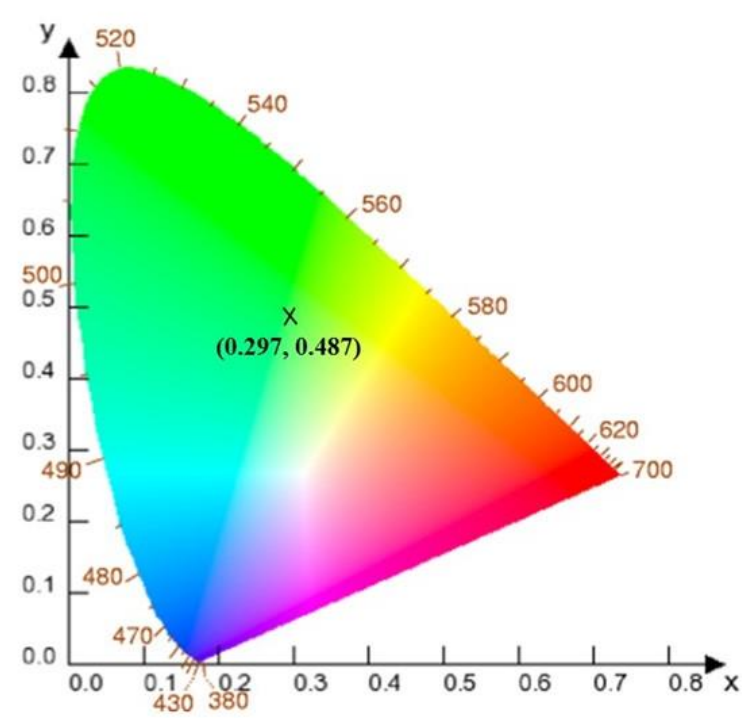

(b)

Figure 5. (a) Photoluminescence Spectrum of TEB at $\lambda_{\mathrm{exc}}=350 \mathrm{~nm}$ (b) Chromaticity Diagram of TEB

TG/DTA. The thermal characteristics of the compound, w.r.t. the decomposition of the crystal at different temperatures can be studied using the thermo gravimetric (TG) and differential thermo gravimetric analysis (DTA). From the TG curve (Figure 6), it can be seen that the compound has very good thermal stability up to $252{ }^{\circ} \mathrm{C}$. A sharp decrease in the weight $(60 \%)$ of the molecule starts at a temperature of $252{ }^{\circ} \mathrm{C}(525 \mathrm{~K})$ and ends at a temperature of 337 ${ }^{0} \mathrm{C}(610 \mathrm{~K})$. The sharp endothermic peak of TEB is a melting peak, which is evident from the solidified melt after getting cooled. The DTA curve gives the inflection point, the temperature at which the greatest weight loss occurs, which for TEB is at $312{ }^{\circ} \mathrm{C}$. 


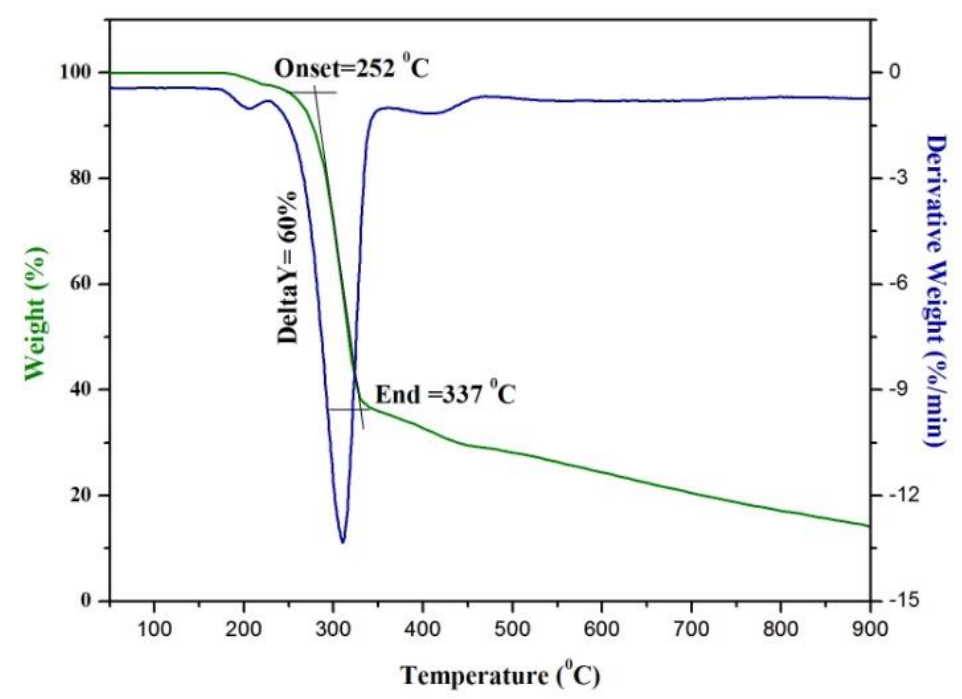

Figure 6. TG/DTA curve

Nonlinear Optical (NLO) Studies. Due to the interaction with the intense laser beam, the molecule shows nonlinear response to the applied electric field. The third order response is experimentally determined using the open aperture Z-scan technique ${ }^{30}$, by which the transmittance of the molecule with respect to the sample position is measured. For maximum beam irradiance, TEB exhibited a linear transmittance (Figure 7) of 59\%, which shows that the molecule can be used as a good optical limiter. The phenomenon responsible for this nonlinear behavior is two photon absorption, which fits well with the experimental data. The two photon absorption co-efficient $(\beta)$ obtained from the experiment can be estimated from the relation ${ }^{1}$

$$
\beta=\frac{2 \sqrt{2} \Delta T}{I_{0} L_{\text {eff }}}\left(\frac{\mathrm{cm}}{W}\right)
$$

where $L_{\text {eff }}=\left(1-e^{-\alpha L}\right) / \alpha, \mathrm{L}$ being the sample length and $\alpha$, the linear absorption coefficient $^{27}$. The value of $\beta$ obtained experimentally for TEB is $43 \times 10^{-12} \mathrm{~m} / \mathrm{W}$. 

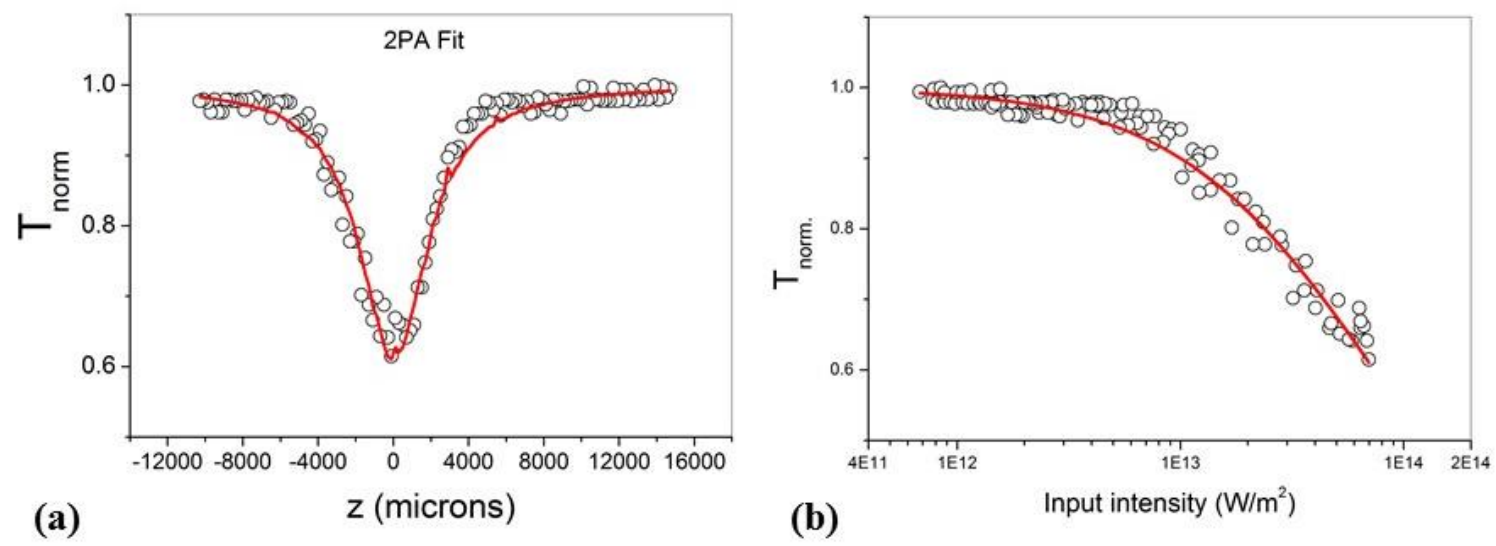

Figure 7. Z-scan curve

Quantum chemical calculations have proven to be a reliable tool for investigating nonlinear optical properties theoretically. The dipole moment that normally has a linear dependence on the electric field now varies nonlinearly in response to the intense laser beam. The Taylor series expansion of the induced dipole moment can be written as:

$$
\mu_{i}=\mu_{0}+\sum_{j} \alpha_{i j} E_{i}+\sum_{j k} \beta_{i j k} E_{i} E_{j}+\sum_{j k l} \gamma_{i j k l} E_{i} E_{j} E_{k}+\cdots
$$

where $\mu_{0}$ is the static dipole moment, $\alpha_{i j}$ is the linear polarizability tensor, $\beta_{i j k}$ is the first order hyperpolarizability tensor and $\gamma_{i j k l}$ is the second order hyperpolarizability tensor. The terms other than the linear component in equation (10) are the second and third order nonlinear components that are responsible for the NLO properties.

Using the diagonal elements of a second rank $3 \times 3$ linear polarizability tensor $\langle\alpha\rangle$, the response parallel to the applied electric field can be found out from the relation: 


$$
<\alpha>=\frac{1}{3}\left(\alpha_{x x}+\alpha_{y y}+\alpha_{z z}\right)
$$

The anisotropy of polarizability is computed using the expression:

$$
\Delta \alpha=\frac{1}{\sqrt{2}} \sqrt{\left(\alpha_{x x}-\alpha_{y y}\right)^{2}+\left(\alpha_{y y}-\alpha_{z z}\right)^{2}+\left(\alpha_{z z}-\alpha_{x x}\right)^{2}+6 \alpha_{x y}^{2}+6 \alpha_{y z}^{2}+6 \alpha_{x z}^{2}}
$$

The first hyperpolarizability $\beta$, being a third rank $3 \times 3 \times 3$ tensor, can be evaluated using the equation:

$$
\beta_{\text {total }}=\left(\beta_{x}^{2}+\beta_{y}^{2}+\beta_{z}^{2}\right)^{1 / 2}
$$

where $\beta_{x}=\beta_{x x x}+\beta_{x y y}+\beta_{x z z}, \beta_{y}=\beta_{y y y}+\beta_{y z z}+\beta_{y x x}, \beta_{z}=\beta_{z z z}+\beta_{z x x}+\beta_{z y y}$

Using the permutations of the $\beta$ components, the values of $\beta(0 ; 0,0)$ \{Static first-order hyperpolarizability\}, $\beta(-\omega ; \omega, 0) \quad$ Frequency dependent electro-optic Pockel's effect\} and $\beta(-2 \omega ; \omega, \omega)$ \{Second Harmonic Generation (SHG)\} can be computed. Of the 27 components of the tensor, 17 have been eliminated by the Kleinmann symmetry ${ }^{31}$ and the remaining ten components are obtained from the Gaussian output. The static and field dependent second hyperpolarizability values with different frequency conditions give insight into the different third order NLO properties. The relations for calculating the second hyperpolarizability values from the Gaussian output $\operatorname{are}^{32}$ : 


$$
\begin{gathered}
\gamma(0 ; 0,0,0)=\frac{1}{5}\left(\gamma_{x x x x x}+\gamma_{y y y y}+\gamma_{z z z z}+2 \gamma_{x x y y}+2 \gamma_{x x z z}+2 \gamma_{y y z z}\right) \\
\gamma(-\omega ; \omega, 0,0)=\frac{1}{5}\left[\gamma_{x x x x}+\gamma_{y y y y}+\gamma_{z z z z}\right]+\frac{1}{15}\left[\gamma_{x x y y}+4 \gamma_{y x y x}+\gamma_{y y x x}\right]+ \\
\frac{1}{15}\left[\gamma_{x x z z}+4 \gamma_{z x z x}+\gamma_{z z x x}\right]+\frac{1}{15}\left[\gamma_{y y z z}+4 \gamma_{z y z y}+\gamma_{z z y y}\right] \\
\gamma(-2 \omega ; \omega, \omega, 0)=\frac{1}{5}\left[\gamma_{x x x x}+\gamma_{y y y y}+\gamma_{z z z z}\right]+\frac{1}{15}\left[2 \gamma_{x y x y}+\gamma_{x y y x}+2 \gamma_{y y x x}+\right. \\
\left.\gamma_{y x x y}\right]+\frac{1}{15}\left[2 \gamma_{x z x z}+\gamma_{x z z x}+2 \gamma_{z z x x}+\gamma_{z x x z}\right]+\frac{1}{15}\left[2 \gamma_{y z y z}+\gamma_{y z z y}+2 \gamma_{z z y y}+\gamma_{z y y z}\right]
\end{gathered}
$$

where $\gamma(0 ; 0,0,0)$ is static second hyperpolarizability, $\gamma(-\omega ; \omega, 0,0)$ represents the optical Kerr effect and $\gamma(-2 \omega ; \omega, \omega, 0)$ depicts the DC-electric field induced SHG.

A comparison of the linear polarizability, first hyperpolarizability and the second hyperpolarizability values of the molecules TEB, Ag-TEB and $\mathrm{Ag}_{3}$-TEB with that of urea is available in the Table 4. Close examination of the polarizability tensor components in each case exposes the fact that the direction in which the dipole moment is having the larger value has an influence in all the polarizability directions. The dipole moment value of TEB molecule is 1.412 Debye, which is contributed mainly by the $\mathrm{z}$ component $\left(\mu_{z}=1.347\right.$ Debye). Therefore, the $\mathrm{z}$ components of the polarizability tensors are showing higher values as compared to the other components of the tensor; i.e., $\alpha_{z z}, \beta_{z z z}$ and $\gamma_{z z z z}$ have the largest values of the corresponding 
tensor elements. $\mathrm{Ag}_{3}$-TEB is also exhibiting similar characteristic where the dipole moment value is 21.228 Debye, that is contributed wholly by the z-component. This value, being much higher than that of pure TEB, is reflected in the other polarizability values also. In the case of Ag-TEB, $x$ component plays the major role in the dipole moment (10.357 Debye; $\mu_{x}=10.314$

Debye) and thereby in the polarizability values also. All the values of linear and nonlinear polarizabilities for normal TEB are greater when compared with that of urea. Further enhancements in the values are obtained when silver atoms are adsorbed, which enables the metal atom adsorbed TEB molecule to be used as a good NLO candidate.

Table 4. Comparison of polarizability values of urea, TEB, $\mathrm{Ag}$-TEB and $\mathrm{Ag}_{3}$-TEB

\begin{tabular}{|c|c|c|c|c|}
\hline $\begin{array}{ll}\text { Parameters } & \text { Molecules } \\
\end{array}$ & TEB & Ag-TEB & $\mathrm{Ag}_{3}$-TEB & Urea \\
\hline $\begin{array}{c}\text { Static Dipole Polarizability } \\
\langle\boldsymbol{\alpha}\rangle_{\text {static }}\left(\times 10^{-24} \mathrm{esu}\right)\end{array}$ & 40.75 & 140.44 & 219.44 & 4.90 \\
\hline $\begin{array}{l}\text { Static Dipole Anisotropy } \\
\qquad \Delta \boldsymbol{\alpha}_{\text {static }}\left(\times 10^{-24} \mathrm{esu}\right)\end{array}$ & 43.91 & 326.32 & 526.34 & 2.03 \\
\hline $\begin{array}{l}\text { Dynamic Dipole Polarizability } \\
\qquad \alpha \boldsymbol{\alpha}\rangle_{\text {dynamic }}\left(\times 10^{-24} \mathrm{esu}\right)\end{array}$ & 42.66 & 10.99 & 44.74 & 4.95 \\
\hline $\begin{array}{c}\text { Dynamic Dipole Anisotropy } \\
\Delta \Delta \alpha_{\text {dynamic }}\left(\times 10^{-24} \mathrm{esu}\right)\end{array}$ & 48.45 & 58.21 & 33.67 & 2.06 \\
\hline \multicolumn{5}{|l|}{ First Hyperpolarizability, $\beta$} \\
\hline $\boldsymbol{\beta}_{(0 ; 0,0)}\left(\times 10^{-30} \mathrm{esu}\right)$ & 83.63 & 964.66 & 222.32 & 0.79 \\
\hline $\boldsymbol{\beta}_{\left(-\omega_{j} \omega_{i}, 0\right)}\left(\times 10^{-30} \mathrm{esu}\right)$ & 120.62 & 830.70 & 1094.11 & 0.85 \\
\hline $\boldsymbol{\beta}_{\left(-2 \omega_{j} \omega_{2} \omega\right)}\left(\times 10^{-30} \mathrm{esu}\right)$ & 353.05 & 1985.67 & 3036.10 & 0.94 \\
\hline \multicolumn{5}{|l|}{ Second Hyperpolarizability, $\gamma$} \\
\hline$Y_{(0 ; 0 ; 0,0)}\left(\times 10^{-36} \mathrm{esu}\right)$ & 294.74 & 6344.84 & 5654.19 & 4.12 \\
\hline $\mathbf{Y}_{(-\omega ; \omega, 0,0)}\left(\times 10^{-36} \mathrm{esu}\right)$ & 457.96 & 5945.86 & 4042.16 & 4.51 \\
\hline$Y_{\left(-2 \omega_{j} \omega_{z} \omega_{j} 0\right)}\left(\times 10^{-36} \mathrm{esu}\right)$ & 1967.10 & 8746.91 & 3970.58 & 5.22 \\
\hline
\end{tabular}

Vibrational Spectral Assignments. Since the molecule consists of 33 atoms, 93 vibrational modes are possible from which information about the functional groups can be obtained. FT-IR and FT-Raman spectra are simultaneously compared with the theoretical 
spectra, for the assignment of peaks. From the PED data of NCA, the contribution of each mode to a particular normal mode is obtained. The region of the spectra above $1500 \mathrm{~cm}^{-1}$ is taken as the characteristic region from which the functional groups of the molecule can be confirmed. Those peaks below $1500 \mathrm{~cm}^{-1}$, i.e. from the fingerprint region ${ }^{33}$, are characteristics of the molecule as a whole. The figures 8 and 9 show the FT-IR and FT-Raman spectra for TEB and the Table S1 (Supplementary Information) gives the assignments.

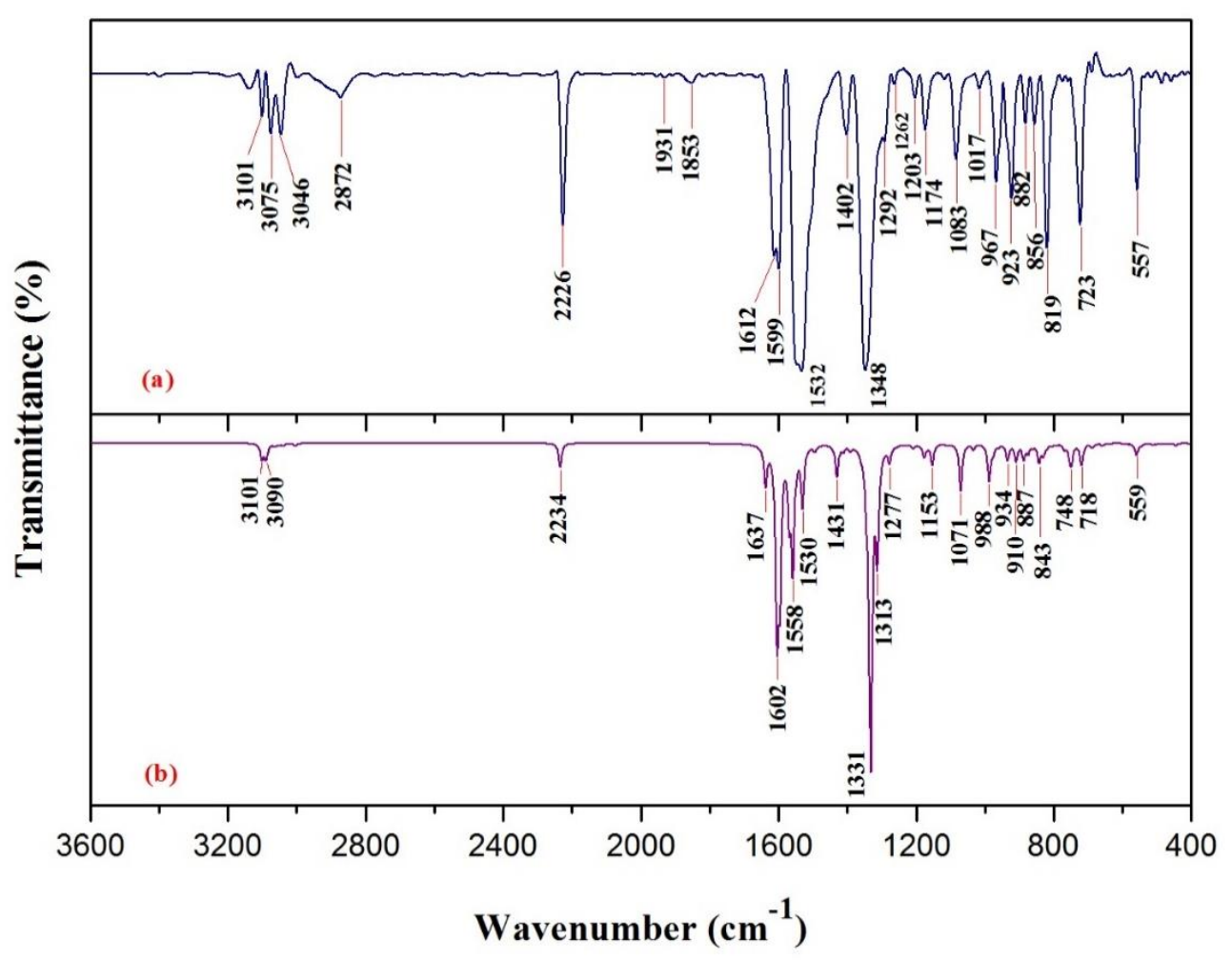

Figure 8. (a) Experimental FT-IR Spectrum (b) Theoretical IR Spectrum 


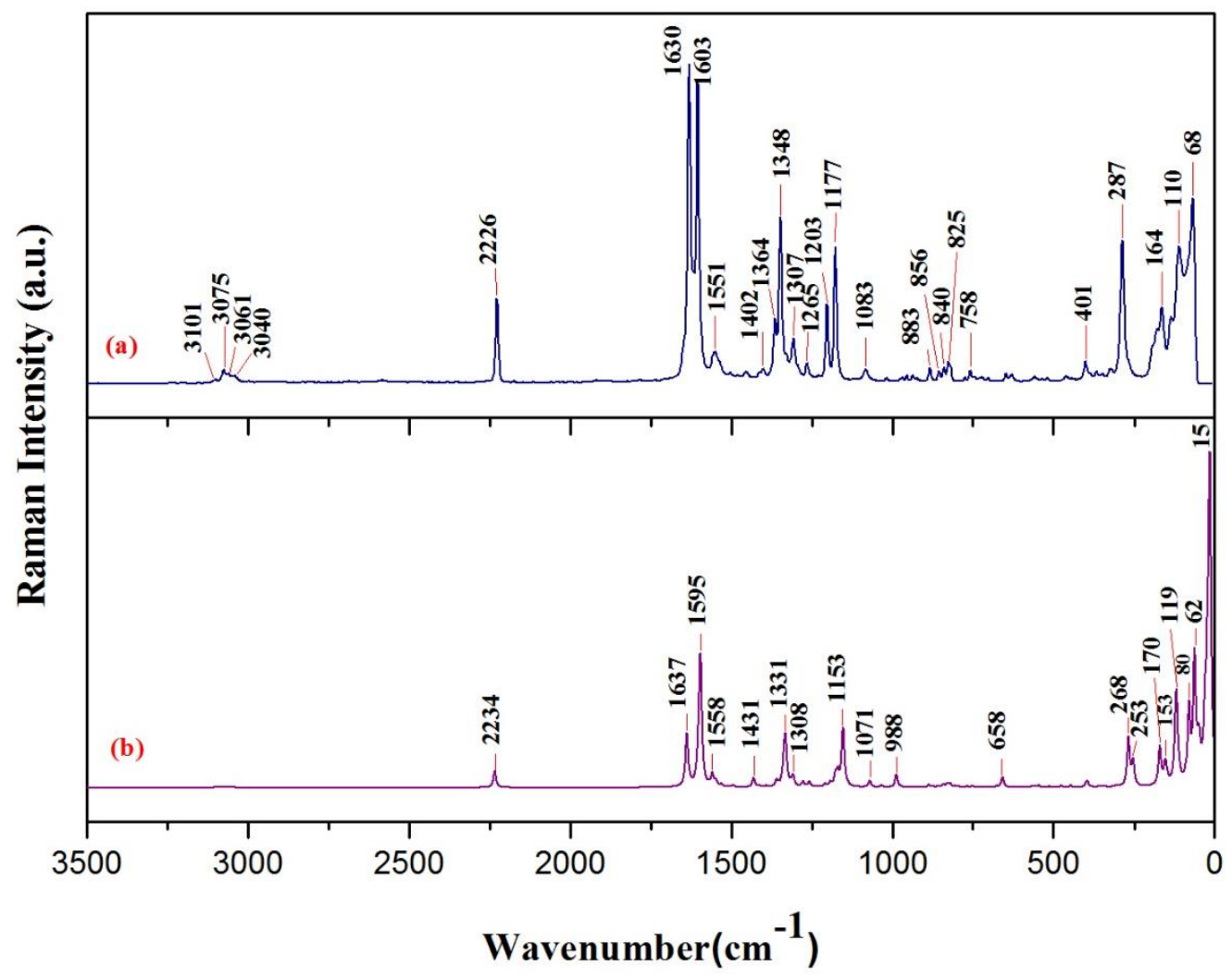

Figure 9. (a) Experimental FT-Raman Spectrum (b) Theoretical Raman Spectrum

Region above $3000 \mathrm{~cm}^{-1}$ (CH stretching vibrations). Usually this region consists of $\mathrm{CH}$, $\mathrm{NH}$ and $\mathrm{OH}$ stretching vibrations. Since our molecule does not contain $\mathrm{NH}$ and $\mathrm{OH}$ bonds, the peaks in this region can be assigned to $\mathrm{CH}$ stretching vibrations that generally occur in the range $3100-3000 \mathrm{~cm}^{-1}$. In the experimental IR spectrum, these modes are observed as weak peaks at 3101,3075 and $3046 \mathrm{~cm}^{-1}$ and in the Raman spectrum as very weak peaks at $3101,3075,3061$ and $3040 \mathrm{~cm}^{-1}$.

Region between 3000 and $1500 \mathrm{~cm}^{-1}$ (CN, CC, NO stretching). The only peak in the region between 3000 and $2000 \mathrm{~cm}^{-1}$ is found theoretically at $2234 \mathrm{~cm}^{-1}$ which is formed due to the $\mathrm{CN}$ stretching of the nitrile group attached to $\mathrm{Ph} 1$. The corresponding peak is observed both in experimental IR and Raman spectra as medium bands at $2226 \mathrm{~cm}^{-1}$. 
In the region between 2000 and $1700 \mathrm{~cm}^{-1}$, the combination tones of the out-of-plane $\mathrm{CH}$ vibrations, called benzene fingers ${ }^{34}$, are seen. Very weak peaks that are overtones or combination bands of fundamental modes appear in this region. Two such peaks are observed in the experimental FT-IR spectrum, one at $1931 \mathrm{~cm}^{-1}$ which can be the overtone of the peak at $967 \mathrm{~cm}^{-}$ ${ }^{1}$ and the other one at $1853 \mathrm{~cm}^{-1}$ that can be the overtone of the peak at $923 \mathrm{~cm}^{-1}$.

A very strong peak found at $1630 \mathrm{~cm}^{-1}$ in the Raman spectrum is assigned mainly to CC double bond stretching vibration of the link between the two rings. A splitting of the band is observed at 1612 and $1599 \mathrm{~cm}^{-1}$ in the IR spectrum, which according to the PED are assigned to the contribution by $\mathrm{NO}$ and $\mathrm{CC}$ stretching of $\mathrm{Ph} 2$. NO stretching of $\mathrm{NO}_{2}$ group has a $55 \% \mathrm{PED}$ contribution to the weak Raman peak at $1551 \mathrm{~cm}^{-1}$. The very strong IR peak at $1532 \mathrm{~cm}^{-1}$ has a contribution from $\mathrm{CC}$ stretching vibration of $\mathrm{Ph} 2$. NO stretching also has contributed to this peak with a PED of $26 \%$.

Region between 1300 and $1500 \mathrm{~cm}^{-1}$ (CH bending and NO stretching). The rocking vibration of $\mathrm{CH}$ bond in the link between the rings is observed theoretically at $1359 \mathrm{~cm}^{-1}$, but observed in the experimental Raman spectrum as a medium peak at $1364 \mathrm{~cm}^{-1}$. On comparison with the theoretical intensity, the simultaneous occurrence of a peak at $1348 \mathrm{~cm}^{-1}$ in both IR and Raman spectra can be attributed to the NO symmetric stretching vibration with a PED contribution of $28 \%$. The $\mathrm{CH}$ bending mode of $\mathrm{Ph} 1$ is observed as a weak peak at $1307 \mathrm{~cm}^{-1}$ in the Raman spectrum.

\section{Region between 1000 and $1300 \mathrm{~cm}^{-1}$ (Ring stretching and bending vibrations).} Corresponding to the theoretical peak at $1258 \mathrm{~cm}^{-1}$, there is a weak peak at $1265 \mathrm{~cm}^{-1}$ in the Raman spectrum which is attributed to the CC stretching vibrations of $\mathrm{Ph} 1$ (53\% PED) and $\mathrm{Ph} 2$ 
(21\% PED). Both IR and Raman spectra consist of a peak at $1203 \mathrm{~cm}^{-1}$ which is attributed to the combined vibrations of $\mathrm{CC}$ stretching in $\mathrm{Ph} 1$, trigonal bending of both rings and $\mathrm{CC}$ stretching of the link between the rings. A strong peak at $1177 \mathrm{~cm}^{-1}$ is observed in the Raman spectrum, with contributions from the $\mathrm{CC}$ and $\mathrm{CN}$ stretching, and $\mathrm{CCH}$ bending vibrations of $\mathrm{Ph} 2$. The peak at $1083 \mathrm{~cm}^{-1}$ in both spectra is also the result of in-plane $\mathrm{CCH}$ bending and CC stretching vibrations of $\mathrm{Ph} 2$.

Region below $1000 \mathrm{~cm}^{-1}$ (Torsional vibrations). Most of the peaks below $1000 \mathrm{~cm}^{-1}$ are affected by the torsional and wagging vibrations of the molecule. The torsion of ring $\mathrm{Ph} 2$ has resulted in the appearance of many of the peaks in this region. The $\mathrm{CCCH}$ wag of $\mathrm{Ph} 1$ has the main contribution $\left(92 \%\right.$ PED) to the theoretical peak observed at $1013 \mathrm{~cm}^{-1}$.

SERS Analysis. The Surface Enhanced Raman Scattering (SERS) technique can be used to find out the type of adsorption between the silver metal atoms and the TEB molecule, whereby the chance of charge transfer from the metal to the molecular orbital can be analyzed. The Figure 10 depicts the profile of the spectrum for different ratios (1:2 and 1:4) of the TEB solution $\left(10^{-5}\right.$ $\mathrm{M}$ and $10^{-6} \mathrm{M}$ ) and the silver nanoparticles. On the investigation of Figure 11 (the Raman spectrum taken for the mixture of TEB solution $\left(10^{-5} \mathrm{M}\right)$ and the silver nanocolloidal solution in the ratio 1:2) a sharp enhanced peak is observed at $2117 \mathrm{~cm}^{-1}$. Since the normal Raman spectrum consists of a peak at $2226 \mathrm{~cm}^{-1}$ which is the only peak in the range $2000-2500 \mathrm{~cm}^{-1}$, the peak at $2117 \mathrm{~cm}^{-1}$ can be undoubtedly assigned to the redshifted $\mathrm{CN}$ stretching frequency (normal range $\left.2225 \pm 15 \mathrm{~cm}^{-1}\right)^{33}$. The shift in frequency for silver-adsorbed molecule is due to the attachment of the silver nanoparticles to the $\mathrm{CN}$ group through the charge transfer from the silver metal orbital to the $\pi^{*}$ orbital of the nitrile group ${ }^{35}$. This extends the $\mathrm{CN}$ bond and the force constant decreases thereby decreasing the wavenumber to a considerable amount. This charge transfer between the 
metal atom and the LUMO of the TEB molecule, termed as chemisorption, is responsible for the shift in the frequencies of the molecule ${ }^{36}$, especially the shift in the stretching frequency of nitrile group to more than $100 \mathrm{~cm}^{-1}$. The chemical enhancement mechanism can also be confirmed from the shift of the comparatively strong band at $2930 \mathrm{~cm}^{-1}$ from above $3000 \mathrm{~cm}^{-1}$ in the case of normal TEB spectrum, assigned to the $\mathrm{CH}$ stretching of the rings. The peak at $1677 \mathrm{~cm}^{-1}$ is a blue shifted TEB peak assigned to $\mathrm{C}=\mathrm{C}$ stretching. The nitro group stretching peak is seen as a sharp one at $1543 \mathrm{~cm}^{-1}$. The presence of the sharp peak at $1055 \mathrm{~cm}^{-1}$ may be the considered as the peak corresponding to $1083 \mathrm{~cm}^{-1}$ in the normal TEB Raman spectrum. The peak at $663 \mathrm{~cm}^{-1} \mathrm{can}$ be assigned to the torsional ring vibrations corresponding to the theoretical peak at $658 \mathrm{~cm}^{-1}$ for TEB molecule. Some peaks, such as 516, 491 and $332 \mathrm{~cm}^{-1}$, which are absent in the normal Raman spectrum of TEB, are now present in the SERS spectrum due to the enhancement effect. These changes in wavenumbers suggest that the TEB molecule is in tilted position with respect to the nanoparticle. The charge transfer property, thus confirmed from the SERS analysis, can be taken as a proof for the use of the molecule as an organometallic ligand capable of increasing the nonlinear optical property of the compound, by extending the donor-acceptor charge transfer.

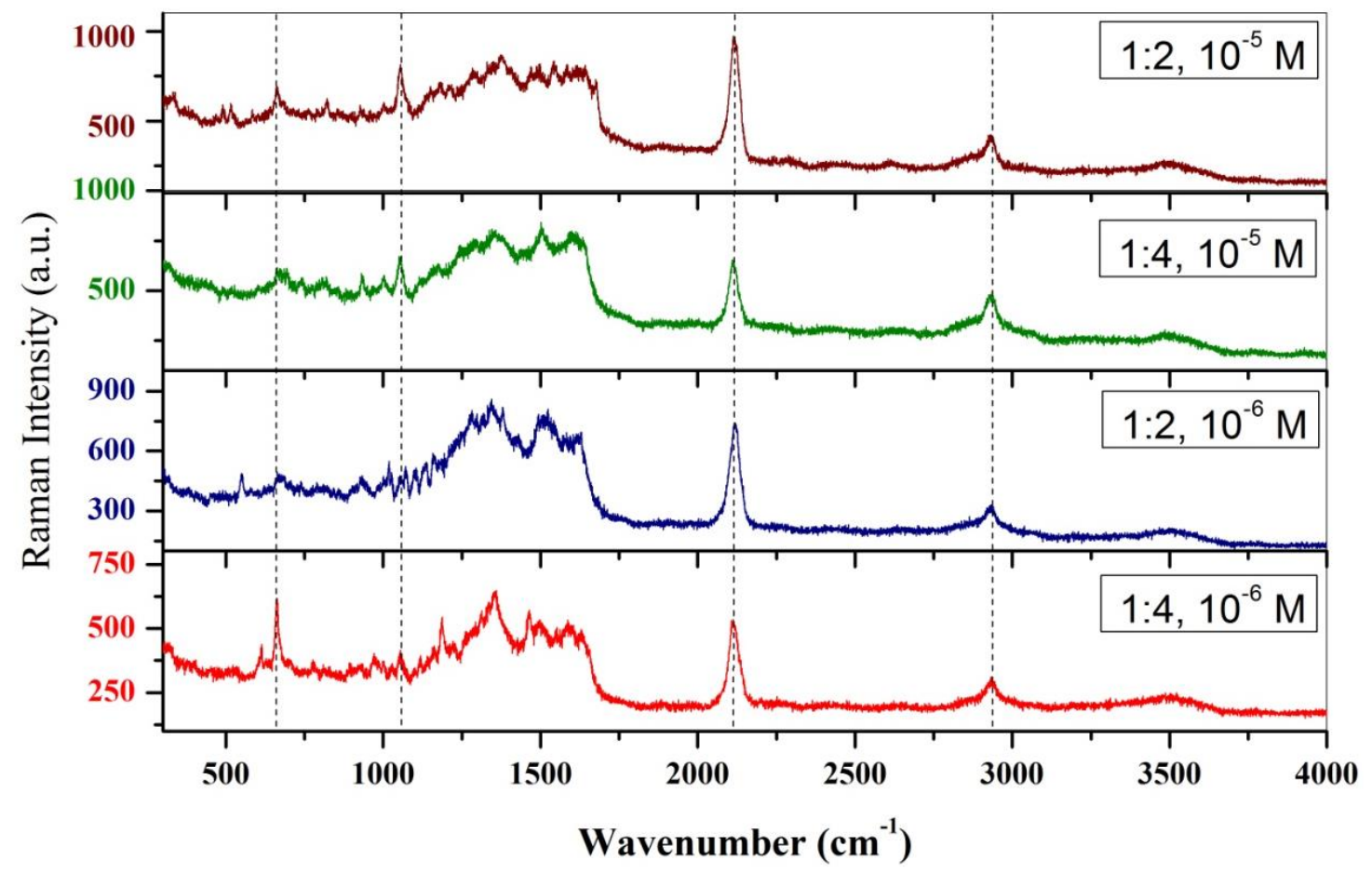


Figure 10. SERS spectrum of TEB molecule in $10^{-5} \mathrm{M}$ and $10^{-6} \mathrm{M}$, mixed with silver nanoparticles in the ratios 1:2 and 1:4.

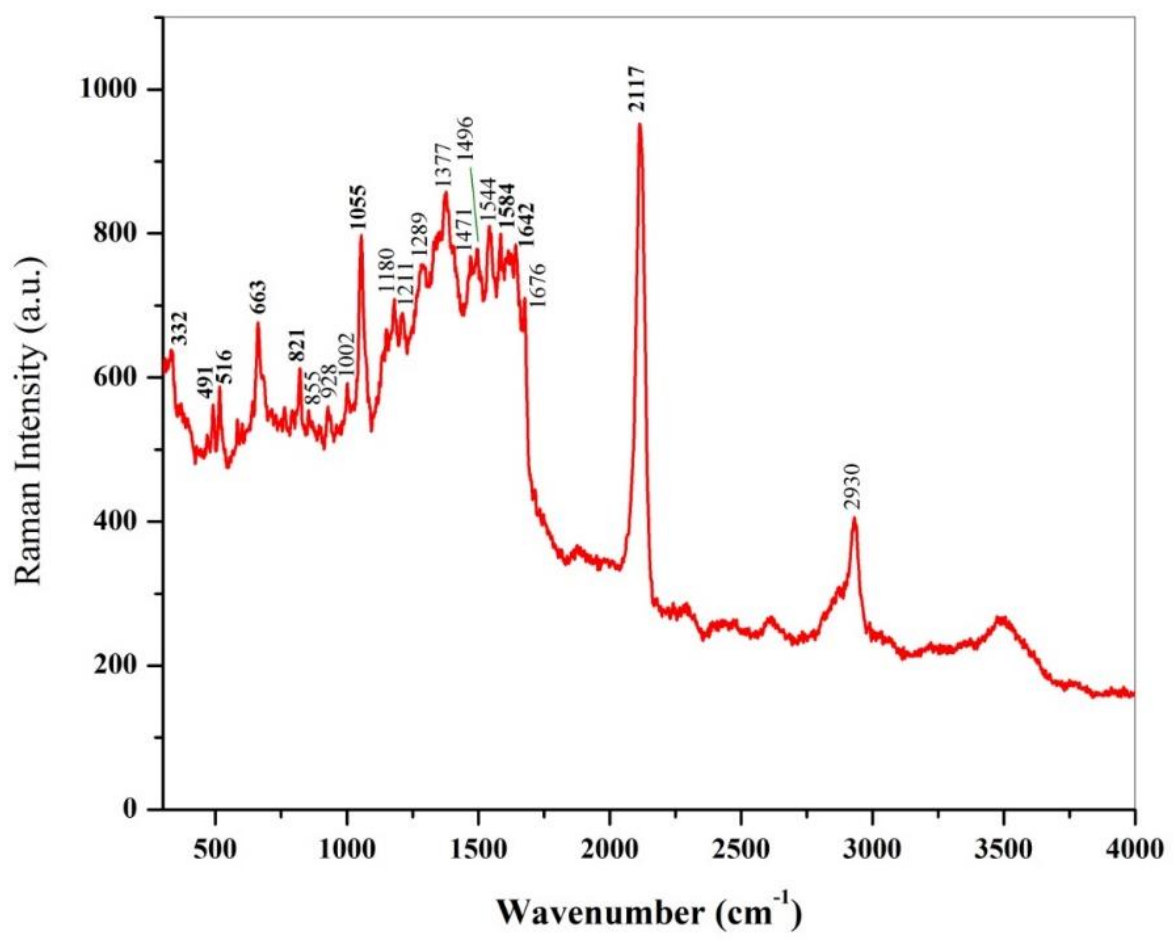

Figure 11. SERS spectrum of TEB solution $\left(10^{-5} \mathrm{M}\right)$ with silver nanoparticles in the ratio $1: 2$ using $532 \mathrm{~nm}$ laser wavelength

A comparison of the unscaled frequencies of pure TEB, Ag-TEB and $\mathrm{Ag}_{3}-\mathrm{TEB}$ is given in the Table S2 along with the Raman spectra (Figure S1) in Supplementary Information.

The effective diameter of the nanoparticles as obtained from the particle size analyzer is $47.7 \mathrm{~nm}$ with polydispersity of 0.360 and the mean zeta potential from the Phase Analysis Light Scattering (PALS) zeta potential analyzer for the colloid solution is $-11.38 \mathrm{mV}$. From the SEM analysis the surface morphology of the nanoparticles is obtained, from which the size and shape of the nanoparticles are found to be in the range 40-50 nm of diameter and in spherical shape, respectively. 


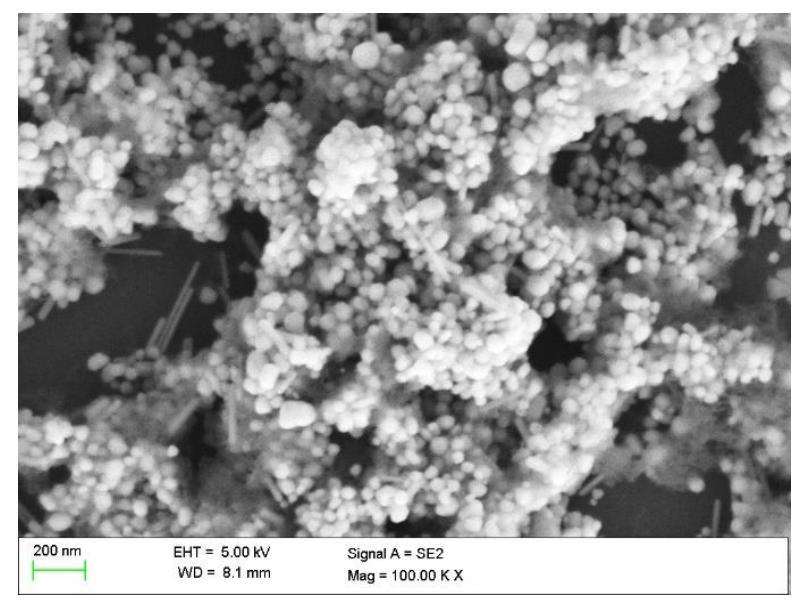

Figure 12. SEM image of the Ag nanoparticles

\section{CONCLUSIONS}

An organic compound that can be used for NLO applications is developed and characterized using theoretical and experimental vibrational spectroscopic techniques. The linear transmittance of less than $60 \%$ shown by TEB in the open aperture Z-scan technique can suggest it for potential optical limiting application. The green light emission of TEB can be applied in light emitting diodes and other photonic applications. Theoretical studies using QTAIM gives information mainly about the interatomic properties while the Hirshfeld surfaces provide the intermolecular interactions. The $\mathrm{Ag}$ and $\mathrm{Ag}_{3}$-attached molecules are also qualitatively analyzed and the variations are observed in the optimized geometry, vibrational spectra, NBO analysis and NLO properties. The experimental confirmation for the chance of $\pi$ backdonation from the metal atom to the TEB molecule is attained by the SERS mechanism. The theoretical NLO study of the silver-attached molecule shows that the hyperpolarizability values are increased further on attachment of the metal atom. 


\section{ACKNOWLEDGMENTS}

The author Jerin Susan John (JSJ) thanks the University Grants Commission (UGC), India, for the award of a Teacher Fellowship under FDP scheme (F.No.FIP/12th Plan/KLKE002 TF04) leading to the Ph.D. degree. The authors (DS and JSJ) thank Frank Blockhuys (Department of Chemistry, University of Antwerp, Belgium) for the help in the synthesis of the organic sample, TEB. The authors (DS and JSJ) also acknowledge the DST-FIST program to the Bishop Moore College Mavelikara for providing the UV -Vis and Photoluminescence measurement facilities. This research (or a portion thereof) was performed using facilities at CeNSE, funded by Ministry of Electronics and Information Technology (MeitY), Govt. of India, and located at the Indian Institute of Science, Bengaluru. The authors (DS and JSJ) are indebted to Dr. Reji Philip (Light and Matter Physics Group, Raman Research Institute, Bangalore, India) for providing the Z-scan measurement facility.

\section{SUPPLEMENTARY INFORMATION}

Table S1. Assignments of peaks using Theoretical and Experimental IR and Raman data

Table S2. Comparison of unscaled theoretical frequencies of TEB, Ag-TEB and $\mathrm{Ag}_{3}-\mathrm{TEB}$

Figure S1. Comparison of unscaled Raman spectra of TEB, Ag-TEB and $\mathrm{Ag}_{3}-\mathrm{TEB}$

\section{REFERENCES}

(1) Jeyaram, S.; Geethakrishnan, T. Third-Order Nonlinear Optical Properties of Acid Green 25 Dye by Z-Scan Method.Opt. Laser Technol. 2017, 89, 179-185.

(2) Motiei, H.; Jafari, A.; Naderali, R. Third-Order Nonlinear Optical Properties of Organic Azo Dyes by Using Strength of Nonlinearity Parameter and Z-Scan Technique. Opt. Laser Technol. 2017, 88, 68-74.

(3) Shi, Z.;Zhou, Y.; Zhang, L.; Hassan, S. U.; Qu,N. Solution Properties and Effect of 
Anions on Third-Order Optical Nonlinearity of Porphyrin-Heteropolyoxometalate Hybrid System.J. Phys. Chem. C 2014, 118, 6413-6422.

(4) Shi, Y.; Xiao, L.; Wu, D.; Li, F.; Li, D.; Zhang, J.;Li,S.; Zhou,H.; Wu, J.; Tian,Y. Synthesis, Crystal Structure, Electrochemistry and Third-Order Nonlinear Optical Properties of Two Novel Ferrocene Derivatives.J. Organomet. Chem. 2016, 817, 36-42.

(5) Shi, Y.; Li, Z.; Fang, Y.; Sun, J.; Zhao, M.; Song, Y. Ultrafast Third-Order Nonlinear Optical Response of Pyrene Derivatives.Opt. Laser Technol. 2017, 90, 18-21.

(6) Assfeld, X.; Rivail, J. L. Ab Initio Local Self Consistent Field Method. Chem. Phys. Lett. 1996, 263, 100-106.

(7) Becke, A. D. A New Mixing of Hartree-Fock and Local Density-Functional Theories. $J$. Chem. Phys. 1993, 98, 2, 1372-1377.

(8) Mattsson, A. E. Density Functional Theory: In Pursuit of the Divine Functional. Science 2002, 298, 759-760.

(9) De Borger, R.; Collas, A.; Blockhuys, F. 4-[(E)-2-(2,4,6-Trinitrophenyl)ethyl- idene] benzonitrile. Acta Crystallogr. Sect. E 2010, 2.

(10) Wenseleers, W.; Gerbrandij, A. W.; Goovaerts, E.; Garcia, M. H.; Robalo, M. P.; Mendes, P. J.; Rodrigues, J. C.; Dias, A. R. Hyper-Rayleigh Scattering Study of $\eta^{5}-$ monocyclopentadienyl-metal Complexes for Second Order Non-linear Optical Materials. J. Mater. Chem. 1998, 8, 4, 925-930.

(11) Garcia, M. H.; Robalo, M. P.; Dias, A. R.; Piedade, M. F. M.; Galvão, A.; Wenseeleers, W.; Goovaerts, E. Organometallic Complexes for Second-Order Non-linear Optics : Synthesis and Molecular Quadratic Hyperpolarizabilities of $\eta^{5}$ monocyclopentadienyliron(II) Nitrile Derivatives with Different Pphosphines. X-ray Crystal Structure of $\left[\mathrm{FeCp}(\mathrm{DPPE})\left(\mathrm{p}-\mathrm{NCC}_{6} \mathrm{H}_{4} \mathrm{NO}_{2}\right)\right]\left[\mathrm{PF}_{6}\right] \cdot \mathrm{CH}_{2} \mathrm{Cl}_{2}$. J. Organomet. Chem. 2001, 619, 252-264.

(12) Garcia, M. H.; Rodrigues, J. C.; Dias, A. R.; Piedade, M. F. M.; Duarte, M. T.; Robalo, M. P.; Nelson Lopes. Second Harmonic Generation of $\eta^{5}$-monocyclopentadienyl ruthenium $p$ - 
benzonitrile Derivatives by Kurtz Powder Technique. Crystal and Molecular Structure Determinations of $\left[\mathrm{Ru}\left(\eta^{5}-\mathrm{C}_{5} \mathrm{H}_{5}\right)((+)-\mathrm{DIOP})\left(p-\mathrm{NCC}_{6} \mathrm{H}_{4} \mathrm{NO}_{2}\right)\right][\mathrm{X}], \mathrm{X}=\mathrm{PF}_{6}^{-}, \mathrm{CF}_{3} \mathrm{SO}_{3}^{-}$and $\left[\mathrm{Ru}\left(\eta^{5}-\mathrm{C}_{5} \mathrm{H}_{5}\right)((+)-\mathrm{DIOP})\left(\mathrm{NCCH}_{3}\right)\right]\left[\mathrm{PF}_{6}\right]$. J. Organomet. Chem. 2001, 632, 133-144.

(13) Wenseleers, W.; Goovaerts, E.; Hepp, P.; Garcia, M. H.; Robalo, M. P.; Dias, A. R. High First Hyperpolarizability and Perfectly Aligned Crystal Packing for an Organometallic Compound $\left[\mathrm{Fe}\left(\eta^{5}-\mathrm{C}_{5} \mathrm{H}_{5}\right)((\mathrm{R})-\mathrm{PROPHOS})\left(\mathrm{p}-\mathrm{NCC}_{6} \mathrm{H}_{4} \mathrm{NO}_{2}\right)\right]\left[\mathrm{PF}_{6}\right] . \mathrm{CH}_{2} \mathrm{Cl}_{2}$. Chem. Phys. Lett. 2003, 367, 2, 390-397.

(14) Lee, P. C.; Meisel, D. Adsorption and Surface-Enhanced Raman of Dyes on Silver and Gold Sols. J. Phys. Chem. 1982, 86, 3391-3395.

(15) Frisch, M. J.; Trucks, G. W.; Schlegel, H. B.; Scuseria, G. E.; Robb, M. A.; Cheeseman, J. R.; Scalmani, G.; Barone, V.; Mennucci, B.; Petersson, G. A. et. al. Gaussian 09, Revision C.01.; Gaussian, Inc., Wallingford CT, 2010.

(16) Sundius, T. Version 7.0 User's Guide; Helsinki, 2002.

(17) Glendening, E. D.; Reed, A. E.; Carpenter, J. E.; Weinhold, F. NBO Version 3.1.

(18) Ebrahimi, A.; Deyhimi, F.; Roohi, H. Natural Bond Orbital (NBO) Population Analysis of the Highly Strained Central Bond in [1.1.1]propellane and some [1.1.1]heteropropellane Compounds. J. Mol. Struct. (Theochem) 2003, 626, 223-229.

(19) Bader, R. F. W. Atoms in Molecules:A Quantum Theory; Clarendon Press, Oxford, 1990.

(20) Sethi, A.; Prakash, R. Novel Synthetic ester of Brassicasterol, DFT Investigation Including NBO, NLO Response, Reactivity Descriptor and its Intramolecular Interactions Analyzed by AIM Theory. J. Mol. Struct. 2015, 1083, 72-81.

(21) Koch, U.; Popelier, P. L. A. Characterization of C-H-O Hydrogen Bonds on the Basis of the Charge Density. J. Phys. Chem. 1995, 99, 24.

(22) Keith, T. A. AIMAll (Version 16.10.31); TK Gristmill Software, Overland Park KS, USA(aim.tkgristmill.com), 2016.

(23) Hirshfeld, F. L.Bonded-atom Fragments for Describing Molecular Charge Densities. 
Theor. Chim. Acta 1977, 44, 2, 129-138.

(24) McKinnon, J. J.; Spackman, M. A.; Mitchell, A. S. Novel Tools for Visualizing and Exploring Intermolecular Interactions in Molecular Crystals. Acta Cryst. 2004, B60, 627668.

(25) Wolff, S. K.; Grimwood, D. J.; McKinnon, J. J.; Turner, M. J.; Jayatilaka, D.; Spackman, M. A. CrystalExplorer (Version 3.1); University of Western Australia, 2012.

(26) McKinnon, J. J.; Jayatilaka, D.; Spackman, M. A. Towards Quantitative Analysis of Intermolecular Interactions with Hirshfeld Surfaces. Chem. Coтmun. 2007, 37, 3814 3816.

(27) Ford, T. A. An ab initio Study of the Properties of Some Lithium-bonded Complexes Comparison with their Hydrogen-Bonded Analogues . 2 . Natural Bond Orbital and Quantum Theory of Atoms in Molecules Analysis. Comput. Theor. Chem. 2014, 1042, 63-68.

(28) Jacquemin, D.; Perpe`te, E. A.; Ciofini, I.; Adamo, C.; Valero, R.; Zhao, Y.; Truhlar, D. G. On the Performances of the M06 Family of Density Functionals for Electronic Excitation Energies. J. Chem. Theory Comput. 2010, 6, 2071-2085.

(29) Jacquemin, D.; Zhao, Y.; Valero, R.; Adamo, C.; Ciofini, I.; Truhlar, D. G. Verdict: Timedependent density functional theory 'not guilty' of large errors for cyanines. J. Chem.

Theory Comput. 8, 1255-1259 (2012).

(30) Sheik-Bahae, M.; Said, A. L. I. A.; Wei, T. Sensitive Measurement of Optical Nonlinearities Using a Single Beam. J. Quantum Electron. 1990, $26,4$.

(31) Kleinman, D. A. Nonlinear Dielectric Polarization in Optical Media. Phys. Rev. 1962, 126, 6, 1977-1979.

(32) Sasikala, V.; Sajan, D.; Joseph, Lynnette; Balaji, J.; Prabu, S.; Srininvasan, P. Spectroscopic and DFT- based Computational Studies on the Molecular Electronic Structural Characteristics and the Third-Order Nonlinear Property of an Organic 
NLOCrystal: (E)-N' -(4-chlorobenzylidene)-4-methylbenzenesulfonohydrazide. Chem. Phys. Lett. 2017, 674, 11-27.

(33) Mayo, D. W.; Miller, F. A.; Robert, H. W. Course Notes on the Interpretation of Infrared and Raman Spectra; John Wiley \& Sons, Inc., Hoboken, New Jersey, 2003.

(34) Varsanyi, G. Vibrational Spectra of Benzene Derivatives; Academic Press, New York and London, 1969.

(35) Robalo, M. P.; Teixeira, A. P. S.; Garcia, M. H.; da Piedade, M. F. M.; Duarte, M. T.; Dias, A. M.; Campo, J.; Wim Wenseleers, W.; Goovaerts, E. Synthesis, Characterisation and Molecular Hyperpolarisabilities of Pseudo-Octahedral Hydrido(nitrile)iron(II) Complexes for Nonlinear Optics: X-rayStructure of $[\mathrm{Fe}(\mathrm{H})(\mathrm{dppe}) 2(4-$ NCC6H4NO2)][PF6]·CH2Cl2. Eur. J. Inorg. Chem. 2006, 2175-2185.

(36) Maiti, N; Thomas, S.; Jacob, J. A.; Chadha, R; Mukherjee, T.; Kapoor, S. DFT and Surface-Enhanced Raman Scattering Study of Tryptophan-Silver Complex. J. Colloid Interface Sci. 2012, 380, 141-149. 